\title{
Dynamic Conditional Correlation between Electricity, Energy (Commodity) and Financial Markets during the Financial Crisis in Greece
}

\author{
Panagiotis G. Papaioannou1, George P. Papaioannou ${ }^{2,3}$, Akylas Stratigakos ${ }^{4}$, Christos Dikaiakos ${ }^{2}$ \\ ${ }^{1}$ Applied Mathematics and Physical Sciences, National Technical University of Athens, Athens, Greece \\ ${ }^{2}$ Research, Technology \& Development Department, Independent Power Transmission Operator (IPTO) S.A., Athens, Greece \\ ${ }^{3}$ Center for Research and Applications in Nonlinear Systems (CRANS), Department of Mathematics, University of Patras, Patras, \\ Greece \\ ${ }^{4}$ Department of Electrical and Computer Engineering, University of Patras, Patras, Greece \\ Email:pgp2ntua@central.ntua.gr,ksiet@mail.ntua.gr,g.papaioannou@admie.gr, c.dikeakos@admie.gr, akylas.strat@hotmail.gr
}

How to cite this paper: Papaioannou, P.G., Papaioannou, G.P., Stratigakos, A. and Dikaiakos, C. (2017) Dynamic Conditional Correlation between Electricity, Energy (Commodity) and Financial Markets during the Financial Crisis in Greece. Journal ot Mathematical Finance, 7, 990-1033. https://doi.org/10.4236/jmf.2017.74055

Received: September 12, 2017

Accepted: November 26, 2017

Published: November 29, 2017

Copyright $\odot 2017$ by authors and Scientific Research Publishing Inc. This work is licensed under the Creative Commons Attribution International License (CC BY 4.0).

http://creativecommons.org/licenses/by/4.0/

\begin{abstract}
Liberalization of electricity markets has increasingly created the need for understanding the volatility and correlation structure between electricity, financial and energy commodity markets. This work reveals the existence of structural changes in correlation patterns among these markets and links the changes to both fundamentals and regulatory conditions prevailing in the markets, as well as the current European financial crisis. We apply a Dynamic Conditional Correlation (DCC) GARCH model to a set of market's fundamental variables, related commodity markets and Greece's financial market and microeconomic indexes to study their interaction. Emphasis is given on the period of severe financial crisis of the Country to understand "contagion" and volatility spillover between these markets. This approach enables us to capture the changing co-movement of assets within and between markets (financial, commodity, electricity) as market conditions change. The main results are that there is strong evidence of volatility spillover (or co-volatility) between financial and commodity market, while the Greek electricity market seems to be almost "isolated" from these two markets.
\end{abstract}

\section{Keywords}

Dynamic Conditional Correlation, Garch, Electricity \& Financial Markets

\section{Introduction}

In the financial and Commodity markets, conditional volatility models have found an extensive application. However the studies focusing on modeling the 
spillover of price conditional volatility between financial, energy (commodity) and wholesale electricity markets in Europe are very few. We provide first a brief literature review.

The transmission of price volatilities between two natural gas markets, the British and Belgium ones, is investigated by Bermejo-Apricio et al., (2008) [1]. They applied GARCH $(1,1)$ and EGARCH $(1,1)$ for the univariate case and a DCC and BEKK (named after Baba, Engle, Kraft and Kroner, Engle, R. F. et al. 1995 [2]) for the bivariate case, on deseasonalized daily prices of National Balancing Point (NBP) and Zeebrugge Hubs. They took also into consideration the Interconnector gas pipeline's used capacity as an exogenous variable for the conditional variance. Their study has shown the existence of an inverse leverage effect for the Zeebrugge and NBP prices i.e. large price increases (positive shock) increase the conditional volatility more than large price drops (negative shock). The main conclusion in their paper is that the Interconnector gas pipeline impacts strongly the conditional variance of NBP and Zeebrugge, resulting in an increase of the volatility linkage between the two markets when $50 \%$ or more of the pipeline's total capacity is used.

The interaction between gas spot prices at Zeebrugge, one month-ahead Brent Oil Prices and temperature, for period 2000-2005, is examined in the work of Regnard and Zokoian (2011) [3]. They used a Vector Error Correction Model (VECM) to investigate the joint dynamics of the three variables and found (using Johansen's approach) evidence of a cointegrating linkage between the three variables. Also, using an asymmetric Constant Conditional Correlation (A-CCC) model and multivariate GARCH have shown that volatilities of the three series are dependent on their own lagged volatilities. They found significant cross-effects in the conditional correlation matrix. They also examine the influence of 3 different temperature regimes on the conditional variance (low temperature regime positive shocks increase the conditional variance, while the Zeebrugge price's volatility is increased due to negative shocks originating from high temperature regime).

The interaction between Brent Oil and NBP spot price returns is estimated by Asche et al. (2009) [4], conducting a multivariate GARCH and a BEEK model. They show that prior to 2003 (a year corresponding to a breakdown), there is not any impact of shocks occurred in the oil (gas) market on the conditional variance of gas (oil). They argue that a possible explanation of the impacts of oil price shocks on the volatility of gas prices is the small or limited available capacity of the European gas market infrastructure as well as the enhanced levels of maturity and liquidity of the European NG spot market.

The volatility spillovers between the $\mathrm{CO}_{2}$, Brent Oil and gas markets in Europe, is the main theme of the paper by Chevallier (2012) [5] and Mansanet-Bataller and Soriano (2009) [6]. In both studies, data of $\mathrm{CO}_{2}$ price series daily futures for the December 2008 contract are used. Daily NYMEX Crude Oil futures and Zeebrugge next month contract prices are used in Chevallier (2012) 
[5] paper, while front month prices for Brent Oil and Natural Gas (NG) are used in the Mansanet-Bataller-Soriano's (2009) [6] paper. Trivariate multivariate GARCH models, namely the CCC, DCC and the BEEK model were used to "capture" the volatility spillovers in Chevallier's (2012) [5] work, while a BEEK model is used in the case of the other paper. The DCC model used in Chevallier's work shows that the conditional correlation between Oil and NG is from -0.3 to 0.3 and for $\mathrm{NG}$ and $\mathrm{CO}_{2}$ is from -0.2 to over 0.1 .

Commodity prices i.e. gas, oil, coal as well as electricity have a strong effect in the determination of Carbon prices, in Phase I of the EU ETS, as shown in the papers of Mansanet-Bataller et al. (2011) [7], Alberola et al. (2008) [8], and Hintermann (2010) [9]. Positive impact on EUA prices is shown to have gas and oil prices. However, the positive impact of Oil prices is ambiguous because this influence may be also attributed to fuel switching effect, to the correlation between oil price and overall macroeconomic conditions or to the Oil-gas price correlation (Rickels et al., 2010) [10]. These above interdependencies are shown in the following simple "causal map" (Figure 1).

Yearly compliance events combined with Regulatory (institutional) and the macroeconomic uncertainties in EUA market have a strong influence on dynamic development of EUA price volatility (Chevallier, 2011a) [11]. In the same work, no evidence was found on the effect of the financial crisis in 2008 on the Carbon price volatility.

Bredin and Muckley (2011) [12], using a cointegration approach, have found an equilibrium linkage (in a new price regime in Phase II) between Carbon futures prices and Energy prices. The main conclusion from this work is that in

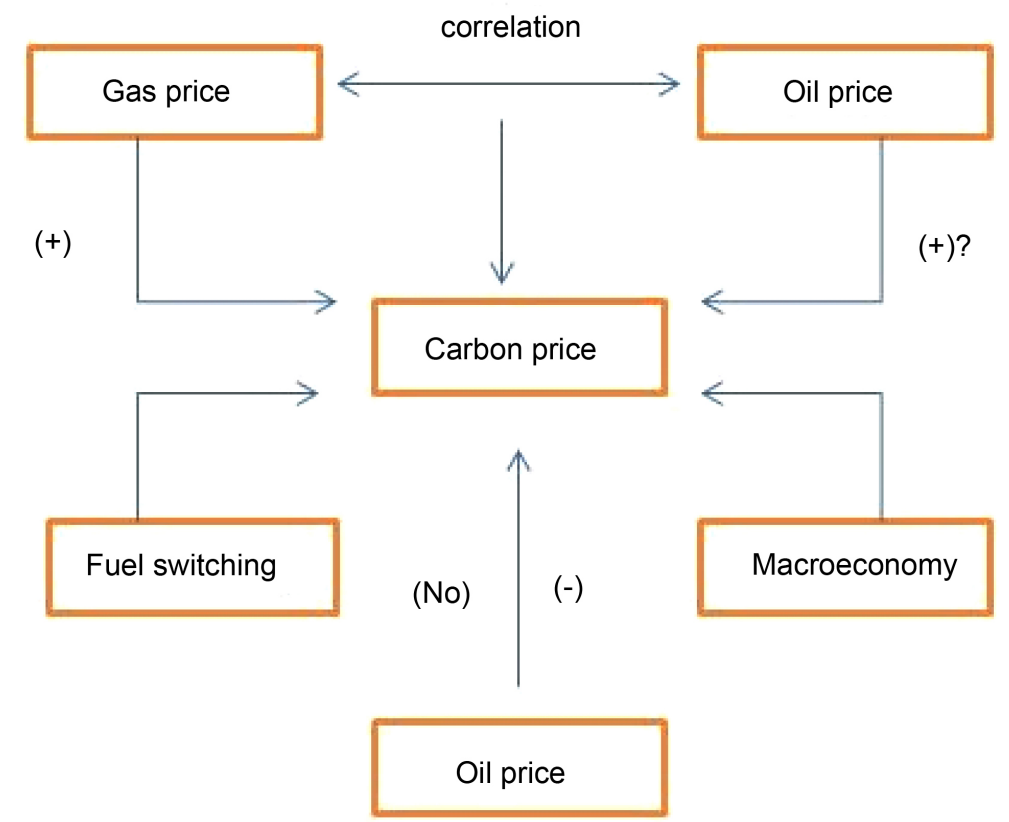

Figure 1. A simple "causal map" showing the main factors affecting Carbon price. 
Phase II the Carbon-energy Co-movement is reinforced, in parallel with a structural increase in correlation patterns.

Another group of literature is concentrated on the mutual interactions between Carbon and Energy market, considering the bi-directional influence. By using a cointegrated VAR method, Bunn and Fezzi (2009) [13] report that gas price affects the EUA price and both jointly affect the equilibrium price of electricity in the UK market. In opposite direction are the results of Nazifi and Milunovich (2010) [14]. They instead found just short-run linkages (s.r.l) between Carbon and Oil, Carbon and gas, and electricity and Carbon, and no long-run relationship between Carbon, energy and electricity prices (shown in Figure 2).

Granger causality tests were performed by Keppler and Mansanet-Bataller (2010) [15], and found that during Phase II, electricity prices Granger cause Carbon prices.

Volatility spillover between Carbon and Energy was examined by Mansanet-Bataller and Soriano (2009) [6] using a BEKK-GARCH model. They found that Carbon volatility is directly and indirectly (via covariance) affected by the Oil and natural gas volatility. Carbon volatility is also affected by shocks coming from Carbon and Oil markets.

Moreover, Koch, N. (2014) [16] has studied the dynamic linkages among Carbon (European Union Allowances, EUA), Commodity (Energy) and financial markets using the Smooth Transition Conditional Correlation (STCC) approach, an extension of DCC model. He calls Oil, gas, coal, electricity, stocks and bonds as accepted fundamentals. He used time as transition variable to allow for structural breaks related to institutional changes in the European Union Emissions Trading System (EU ETS). His main conclusion is that correlation depends on market uncertain conditions, reflecting the connection between Carbon and Financial markets due to common macroeconomic shocks happened over the 2008/09 financial crisis.

The linkage between EUA and Financial markets as described in Koch's [16] work serves as a firm basis on which we build our work. The component "EUA-financial and electricity markets linkage" or more precisely the volatility spillover between eua-financial markets, is depicted in the following triplet "causal map" (Figure 3).

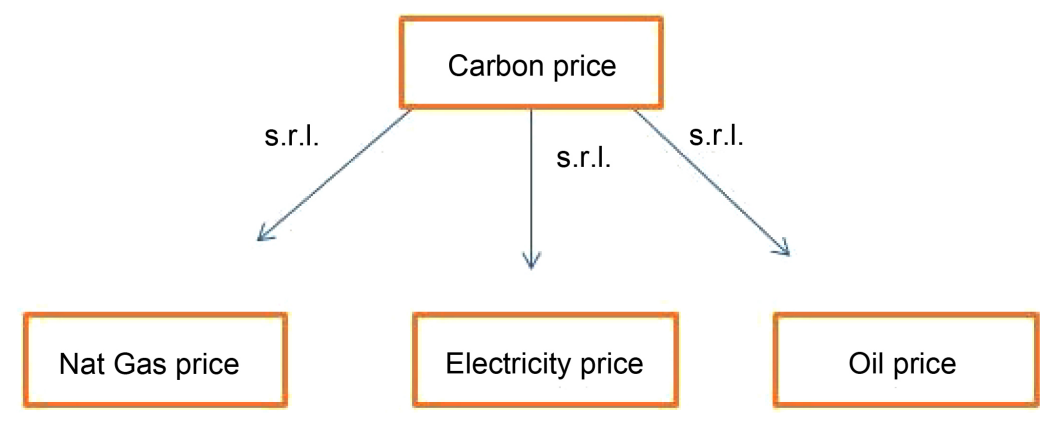

Figure 2. Short run linkages (s.r.l.) between carbon price and natural gas, electricity and oil price. 


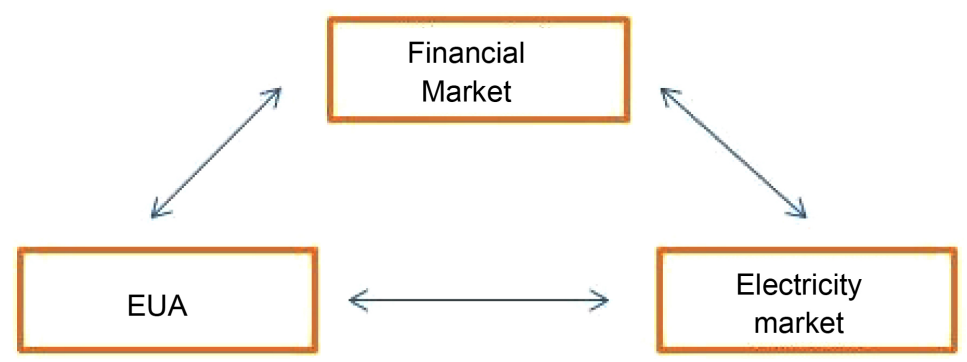

Figure 3. Interdependence between the financial, energy and electricity markets.

We share Koch's [16] argument on the existence of correlation asymmetries due to time-varying market uncertain conditions and examine in our work here the influences of these conditions on the dynamic conditional correlations during periods of calmness and turmoil in financial markets. This is of particular value in the case of Greece, a State hit heavily by two crisis, the financial one 2008-2009 and the Greek Debt (Sovereignty) crisis started in late 2010.

We must note that in this study, we refer as "financial crisis" to the Subprime mortgage crisis, which spans from 2008 to late 2009 in our sample, and as "Greek debt crisis" to the European sovereign debt crisis of late 2009.

The rest of the paper is organized as follows. In Section 2 we describe the macroeconomic risk factors and stretch the significance of volatility spillover or co-movement, between 3 different markets: financial, energy commodity and Power (electricity) markets. The used data sets and a short description of the Greek electricity market and financial market are given in Section 3. Section 4 provides all necessary information on the methodology (DCC, CCC etc) used in this work and finally the empirical findings are presented in Section 5 followed by Conclusions in Section 6 .

\section{Macroeconomic Risk Factors and the Significance of Volatility Spillover or Co-Movement}

The importance of macroeconomic risk factors in shaping the expectations of the equity, bond and commodity markets, has been "stressed" by Fama and French (1989) [17] and Sadorsky (2002) [18]. These factors are assumed in this work to influence Carbon, Energy and Electricity markets (Chevalier, 2009) [19]. Thus, we expect the EUA price to fall if there is a prospective economic slow-down, indicated by the macroeconomic indicators. This is a rational expectation since adverse business conditions lower aggregated demand and thus reduce the demand for electricity (load), the generation output, the demand for coal and as a consequence the demand for EUA. The two stock indices Athens Stock Exchange (ASE), Euro stoxx 50 and vstoxx (for volatility) are considered, as well as the 10-year Greek Government Bonds as measures for macroeconomic and financial risks in Greece and Europe respectively (please refer to section 3 for a more detailed description). The stock indices measure the development of the financial markets and are used to predict the fluctuations of the general eco- 
nomic "climate".

\subsection{The Importance of Input Fuel Prices Volatilities and Their Co-Movement with EUA}

The operational behavior that links fuel and EUA is the generator's fuel-switching. This is so because a higher gas (coal) price ends up to a higher (lower) eua:

$$
\begin{array}{r}
\text { ngasUK } \uparrow \text { then eua } \uparrow \\
\text { coal } \uparrow \text { then eua } \uparrow
\end{array}
$$

This observation is a good theoretical basis for explaining the co-movement or the Dynamic Conditional Correlation between input fuel prices and eua. A producer of electric power uses hydrocarbon fuels and eua as production inputs, so he depends on these "assets". This situation is not the same as in a financial market in which a portfolio manager can diversify his assets portfolio by altering the (percentage) share of the assets, in order to protect the value of the portfolio from price changes (hedging). The power producer is exposed to changes in prices in electricity, energy (commodity) and EUA markets. Therefore, the risk-averse Power Plant Owner (producer) has to operate in forward (futures) markets for hedging his profits against the risk of unpredictable and unfavorable price volatility. In other words he tries to lock in a given profit based on a given (assumed) marginal generation cost.

However, the key variables in a futures market are the price volatility of an "asset" (input fuel, eua etc.) and its co-movement with other relevant asset's price. This co-movement is measured by its conditional covariance or correlation price volatility is usually expressed as conditional variance.

Following Koening, P. (2011) [20], in order to realize how a Power Producer is exposed to eua and fuel price co-movements, we recall the marginal generation Cost $M C_{p}$ in $€ / G J_{e}$ of generating a given unit of power, by using as input fuel $i$ :

$$
M C_{i}=\frac{F C_{i}}{n_{i}}+\frac{E F_{i}}{n_{i}} E C
$$

where $F C_{i}$ is the fuel cost in $€ / G J, n_{i}$ is the power plant net thermal efficiency in $\mathrm{GJ}_{\mathrm{e}} / \mathrm{GJ}\left(\mathrm{GJ}_{\mathrm{e}}\right.$ is the power output in gigajoule of electricity, GJ the power input in gigajoule of fuel), $E F_{i}$ the Green House Gas (GHG) emission factor in $\mathrm{kg}$ $\mathrm{CO}_{2} / \mathrm{GJ}$ and $\mathrm{EC}$ is the GHG emission cost in $€ / \mathrm{kg} \mathrm{CO}_{2}$. Equation (1) is actually a simplification and $M C_{i}$ is primarily estimated by the variable costs of fuel and $\mathrm{CO}_{2}$.

The variance of $M C_{i}$ is given by (Koening, P., 2011) [20]

$$
\sigma_{M C_{i}}^{2}=\frac{1}{n_{i}^{2}} \sigma_{F C_{i}}^{2}+\frac{E F_{i}^{2}}{n_{i}^{2}} \sigma_{E C}^{2}+2 \frac{1}{n_{i}} \frac{E F_{i}}{n_{i}} \rho_{F C_{i}, E C} \sigma_{F C_{i}} \sigma_{E C}
$$

where $\rho_{F C_{i}, E C}$ is the correlation of input fuels and eua and $\sigma_{i}^{2}$ are variances. Equation (2) is a risk measure, related to $M C_{i}$. In this paper will show that the pairwise correlations between electricity, fuel and eua are time-varying and also 
will examine how the volatility in Energy commodity markets in combination with volatility in financial markets affect the above conditional correlations.

\subsection{The Correlation of Carbon Emission Allowances (Eua) with Other Commodity Prices (NgasUK, Brent, Coal or Lignite)}

The optimal merit order of power generation is affected by changes in the relative price of input fuels. These changes ultimately result in a fuel-switch, by the power generator which tries to maximize its profit. Fuel-switching is not an observable operational variable and has to be inferred from changes occurred in the relative marginal costs.

From the above we conclude that the unobserved fuel-switching behavior by generators is the main factor of "producing" the correlation between input fuels (brent, ngasUK) and carbon emission allowances (eua). The empirical Carbon price moves between two extreme values, the upper bound theoretical switch price $S \boldsymbol{P}_{u}$ defined as the price of $\mathrm{CO}_{2}$ above which natural gas is the preferred input fuel (technology), no matter what the thermal characteristics of the generation mix (or plant portfolio) (Koening, P., 2011) [20]. $S P_{u}$ is given by

$$
S P_{u}=\frac{n_{\text {coal }}^{E} F C_{\text {gas }}-n_{\text {gas }}^{I} F C_{\text {coal }}}{n_{\text {gas }}^{I} E F_{\text {coal }}^{E}-n_{\text {coal }}^{E} E F_{\text {gas }}^{I}}
$$

where $n_{\text {coal }}^{E}$ and $E F_{\text {coal }}^{E}$ are the thermal efficiency and emission factor of the most efficient coal fired power plant in a Country's generation mix (plant portfolio). The thermal efficiency and emission factor of the most inefficient gas fired power plant are $n_{\text {gas }}^{I}, E F_{\text {gas }}^{I}$ respectively. Therefore, if the price of carbon increases then it will motivate generators to switch input fuels from Coal (Lignite) to gas. As soon as $\mathrm{CO}_{2}$ price has attained $S P_{u}$, even generators that have a choice between the most inefficient gas and most efficient Coal plant, will have, at the end, to "move" to natural gas generation. So, there is no other technology feasible generation mix which prefers coal over gas generation. An electricity producer, a profit maximizing "rational" market player, will switch generation from using Coal (lignite) to using natural gas, just in the case of the empirical emission price exceeds the $S P_{u}$.

The lower bound theoretical switch price, $S P_{p}$ is the price of Carbon below which Coal is the preferred input fuel, irrespective of the thermal characteristics of the generation mix (Koening, P., 2011) [20].

$$
S P_{l}=\frac{n_{\text {coal }}^{I} F C_{\text {gas }}-n_{\text {gas }}^{E} F C_{\text {coal }}}{n_{\text {gas }}^{E} E F_{\text {coal }}^{I}-n_{\text {coal }}^{I} E F_{\text {gas }}^{E}}
$$

where $n_{\text {coal }}^{I}, E F_{\text {coal }}^{I}$ the thermal efficiency and emission factor, respectively, of the most inefficient coal fired plant in a Country's generation mix. $n_{g a s}^{E}$ and $E F_{\text {gas }}^{E}$ are the thermal efficiency and emission factor, respectively, of the most efficient natural gas fired plant in the Country's generation mix.

Thus, if the Carbon price decreases it will give the motivation to generator to switch input fuels from natural gas to Coal power generation. When carbon 
price reaches $S P_{p}$ all generation "players" will have to switch to Coal, even though they have the choice between the most inefficient Coal and the most efficient natural gas plant.

From the above, the main conclusion is that a higher share of Coal production (Lignite in the case of Greece), rationally, will increase the demand for Carbon emission allowances (eua) and its price will go upwards again.

Combining all the above the empirically observed EUA (eua time series) is expected to move between the two time-varying extreme values, $S P_{l}$ and $S P_{u}$. From the definitions given by (3) and (4), two correlation regimes are possible between eua and other commodities (ngasUK, Brent, Coal, Lignite). The first is when eua (empirical carbon price) either exceeds $S P_{u}$ or falls below $S P_{b}$ a situation referred as Static merit order. In this case either natural gas or Coal is clearly the preferred input fuels and small changes in their prices do not change the merit order. In this case there is no financial motivation to switch input fuels, which results in an unchanged demand for eua and eua therefore fuel prices are decoupled. The second correlation regime is when eua is between $S P_{l}$ and $S P_{u}$.

Here we have a mixed merit order in which there is no clear ranking of the input fuels in the merit order and the crucial now factor in choosing one of the two fuels is their thermal efficiencies. This is a situation where small fuel price changes have a strong influence in the merit order, which in turn result in changes of demand for eua. This fuel and eua prices are coupled (or co-move). The coupling and decoupling of eua and fuel prices have been studied in depth by Koening P. (Koening, P., 2011 [20]). A very important conclusion from his work is that if in a period the relative forward (futures) fuel and eua prices are in such levels that make a constant merit order, then these prices are decoupled, exhibiting a low correlation. The above situation calls for an alternative hedging strategy for securing a profit one month ahead, in comparison with a situation with coupled prices and strong correlation.

In theory, the equilibrium allowance price is equal to the marginal abatement costs incurred to reduce one ton of pollutant (Springer, 2003) [21]. The papers by Rubin (1996) [22] and Tietenber (2006) [23] describe the theoretical basis of deterministic equilibrium models and the solution, in a cap-and-trade framework, of the firm's pollution cost optimization problem. Thus, the participants of the market take only these measures whose costs are less than or equal to the EUA price. The theoretical justification of linking Carbon and Commodity (Energy) markets lies in the difficulty to find proxies for the emission abatement costs of a firm and their availability.

A rational abatement method is the fuel switching (Delarue, E. et al., 2008) [24]. This method allows the power producers to abate emissions without reducing the output or making new Power plants and also take advantage of the fact that within EU ETS market the dominant player are the Power firms (representing almost $70 \%$ of the total allowances, Trotignon and Delbose, 2008 
[25]. Therefore, it is expected that input fuel prices and Carbon prices must be correlated, according to the requirement of an efficient market.

\subsection{The Interaction of Financial and EUA Markets}

Koch, N. (2014) [16] has found that EUA and financial markets are not isolated. Rather, financial market conditions impact strongly the correlations and the vstoxx index serves as an informative state variable reflecting the risk of "genetic" financial turmoils related to extreme events in the stock markets. According to Koch, N. (2014) [16], the correlation between EUA Stock and Bonds (eua, ase, gbonds in our case) is expected to be strongly affected by an expected high volatility. The correlation fluctuates upwards (downwards) with peaks reverting around the collapse of Lehman Brother. He also found an impressive commonality in the EUA-Brent and EUA-Stock time-varying linkages, indicating that the positive impact of Brent Oil is possibly due to the interaction of Brent Oil prices and the overall macroeconomic situation and not due to the fuel switching (see below) or Oil-Natural gas correlation.

It is well known that macroeconomic conditions (economic growth) affect heavily both EUA and financial markets. An increased demand and raised industrial production is the result of high economic activity, which in turn increases Carbon emissions therefore increases EUA (Ellerman and Buchner, 2008) [26]. Alberola et al. (2009) [27] provide evidence of a moderate effect of Industrial production on EUA prices. Considering the Stock index as a "physical" economic indicator, Hintermann (2010) [9] has found no significant influence of Stock Index on EUA prices in Phase I of the EU ETS, while Bonacina et al. (2009) [28] confirm that there is a correlation between EUA prices and Euro Stoxx 50 (stoxx) in the first trading year of Phase II. Chevallier (2009) [10] document that some particular economic factors like default spread, dividend yield or short-term interest rate are weakly correlated with EUA price, although these factors have a good forecasting power in Stock, Bond and commodity markets. Such common influences on the EUA market are not evident as Bessembinder and Chan (1992) [29] have also observed. Furthermore, Daskalakis et al. (2009) [30] provides strong evidence on significant negative unconditional correlations between EUA and Stock markets during 2005-2007. On the opposite, Gronwald et al. (2011) [31] provide a strong positive Carbon-Stock markets dependence, which is higher for Brent Oil and Natural gas, by using Copula analysis. The impact of financial market turmoil on EUA market correlation with Stock price indices is assessed in the paper by Kanamura (2010) [32]. A multivariate correlation model was applied and provided evidence of an increased correlation in times of stock market plunge, called also contagion. The paper also suggests a reduction in correlation during the oversupply event, occurred in April 2006.

Carbon and Financial Markets

The Carbon market, therefore, can be characterized as a peculiar market, not in- 
fluenced heavily be macroeconomic variables, and that the supply and demand of allowances is the main mechanism setting the equilibrium prices.

On the other hand, Borak et al. (2006) [33], Benz and Truck (2006) [34] consider Carbon as a "new" input production variable that increases the cost of generation therefore exerting pressure and uncertainties on the profits thus on the Stock market as well. They argue that EUA and Stock exhibit an indirect correlation.

The Stock market effect of the EU ETS is examined also by Veith et al. (2009) [35] and surprisingly they identified a positive correlation between EUA prices and Stock price returns of "big" European Utilities.

The way with which the inclusion of EUAs in an assets portfolio improves the investment opportunity is examined by Mansanet-Bataller (2011) [7] in which he finds that the opportunity set does not vary with the inclusion of Phase II EUAs, a result opposed to the one found by Chevallier, J. (2009b) [36]. It is shown, furthermore, in the above two latter papers that EUA returns are slightly negative and statistically non-significantly correlated with fixed-income securities (like Government Bonds). This result in combination with Koch, N. (2014) [16] results is our motivation to include the Greek Government Bonds in this study, using a DCC model as opposed to the CCC models used in Mansanet-Bataller and Chevallier papers.

\subsection{The Interaction between $\mathrm{CO}_{2}$ and Electricity Prices}

Low electricity prices encourage higher electricity consumption, resulting in higher $\mathrm{CO}_{2}$ emissions. Therefore the demand for allowances may increase in case electricity utilities are not in compliance with their initial allocation, a fact that in turn exerts strong pressure of the EUA markets. A further consequence is that the increase in $\mathrm{CO}_{2}$ prices and generation costs may increase electricity prices creating the need for a demand adjustment, which of course implies some level of price elasticity.

Observed power and $\mathrm{CO}_{2}$ prices are influenced also by fuel prices. If the prices of natural gas are increased then there is a strong incentive for generating base-load electricity by using more Coal-or Lignite fired-Plants, driving up, in turn, the demand for $\mathrm{CO}_{2}$ allowances. It is worth to mention here that Coal-fired generating units emit almost twice as much $\mathrm{CO}_{2}$ as natural gas generating units. If the situation just described is sustained and the supply of allowances is not adequate, $\mathrm{CO}_{2}$ prices may increase at a level that result in a fuel switch i.e. natural gas, a cleaner fuel. This "cause and effect" relationship has predicted a lot of the early $\mathrm{CO}_{2}$ price volatility due to the switching from Coal (Lignite) to gas. Using the cointegration approach, Bunn and Fezzi (2007) [13] have analyzed the impact of EU ETS on electricity and gas prices.

\section{The Data Sets}

In this paper we consider daily data covering the period for April, 2008 to March 
2014, a total of 2160 observations. The analysis period is divided into 2 periods: a) the Subprime Crisis period (from April 2008 until the end of 2009) and b) the Greek Government Debt Crisis (early 2010 until April 4, 2011). The two periods correspond to the two shaded areas in the DCC plots (Section 5.2). The chosen sampling frequency produce sufficient number of data required to measure the dynamics of correlations which may vary due to periods of financial turmoil of differing durations. The price data are denominated in the local currency of each market. To enhance our choice of data frequency, we point out that from an EU ETS participant point of view, caring for his risk management, high frequency (here daily) correlations are more useful that long-term correlations. The data sets are obtained from various resources, Athens Stock Exchange (ASE), Independent Power Transmission Operator (IPTO), Intercontinental Exchange (ICE) Futures Europe, Energy Information Administration (EIA) and Bloomberg.

\subsection{The Carbon Market and the EUA Data}

The three phases of the EU ETS, corresponding to the three compliance periods are Phase I: 2005-2007, Phase II: 2008-2012 and Phase III: 2013-2020. The pilot period of the EU ETS is the well-known to market participants Phase I. The National Allocation Plans (NAPs) determine the overall emission cap for Phase I and Phase II. Each member state determines its NAP, defining actually the total permits and the allocation mode. NAPs are approved by European Commission (EC), which settles the overall cap. Because neither borrowing nor banking of EUA (EU Allowances) were allowed between Phase I and Phase II, the price for EUAs (series eua in this paper) issued for Phase I collapsed. The first information regarding the actual EUAs released in April 2006, however the market participants considered that the total emission cap for Phase I was not restrictive. Phases II and III are linked by banking, where the transactions of spare EUAs enlarges the time period considered by the agents when they shape their expectations about the overall shortage of EUAs. The Banking involvement reduces, therefore, the risk of an extreme collapse of the EUA price. But, if shocks happen they still can generate strong price and volatility fluctuations. Highly efficient EUA spot and derivative markets have evolved since 2005 and the most liquid derivative market is the European Climate Exchange (ICE/ECX, London), where $90 \%$ of the futures contracts are traded.

\section{Description of the Data}

Daily settlement prices of EUA futures contracts (€/ton) traded on the ICE ECX are used to form a continuous price time series that combines a number of contracts expiring in Phase II and III (2008-2012 and 2013-2020), following the approach of Koch, N. (2014) [16]. We mention here that trading of EUA futures contracts started not until April 22, 2005. The price of the 2008 contract constitutes the continuous carbon price time series during Phase I. This series changes to the December 2009 contract in Phase II, up to the last trading day, on which 
day the series changes again into the next yearly contract. According to Koch (2014) [16] this method of constructing the continuous EUA series is unlikely to introduce a bias because the used futures contracts are not redeemable in Phase I. This choice in forming the EUA series is further enhanced by the fact that EUA are required only once a year, for the reason of compliance, so holding spot EUAs does not offer any advantage in comparison with holding a corresponding futures position (Daskalakis et al., 2009) [29]. Also, Koch (2014) [16] concludes that the EUA futures prices for Phase II can be considered as the reliable "real" price signal for investors. We have used EUA data, Phase II, obtained from ICE ECX market because this is the leading exchange (Mizrach and Otsubo, 2011) [37].

\subsection{The Commodity (Energy) Data. Natural Gas Prices at NBP Hubs and the Greek Natural Gas "Market"}

We use daily spot price of Brent Oil traded in Euro/barrel. For natural gas historical 1 month ahead futures prices, traded at the National Balancing Point NBP Hub UK, expressed in $€ / M W h$, are considered, obtained from ICE. Since the late 1990s, UK NBP Hub gas market is Europe's longest established wholesale (spot-traded) market in operation (Figure 4). This wholesale gas market is the most liquid one in Europe nowadays, alongside a number of newly established Continental Europe hubs (e.g. Zeebrugge in Belgium and TTF in Netherlands) NBP is the acronym for National Balancing Point and gas anywhere in UK within the NGNTS (Natural Gas National Transmission System) counts as NBP gas. This Hub brings together buyers and sellers so the trading is greatly simplified. There is a variety of products: within-day (for same day delivery), day-ahead (for next day delivery), months, quarters, summers (April to September)

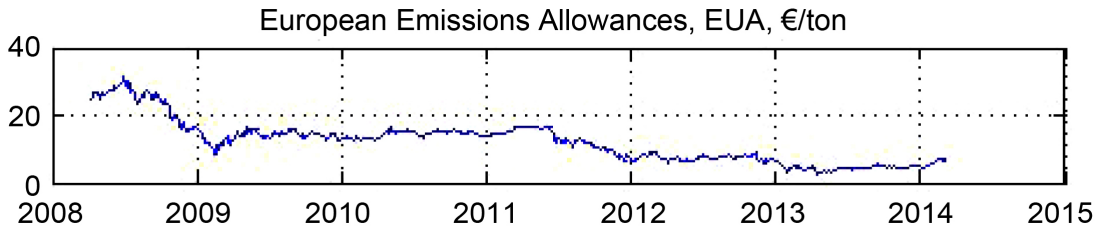

Natural Gas 1 month futures, NBP Hub, €/MWh

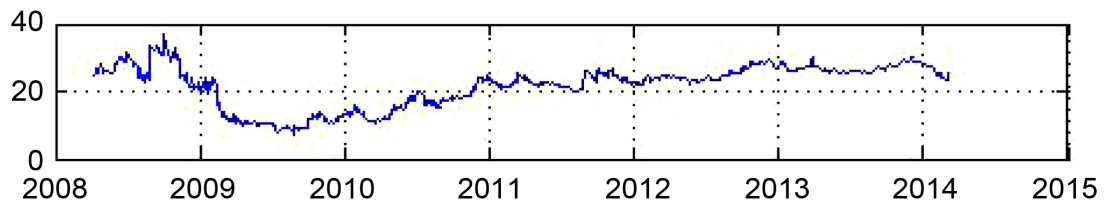

Brent Oil, in \$/bbl

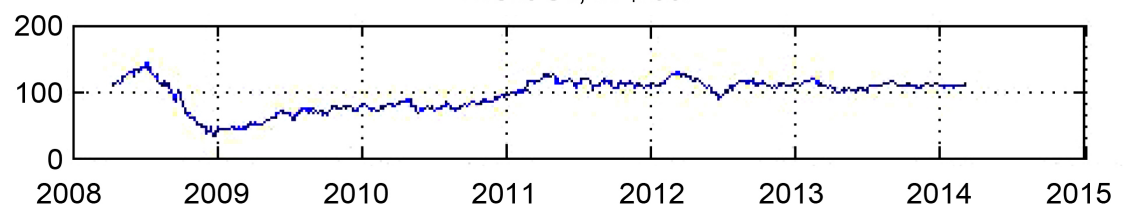

Figure 4. EUA, Natural gas and brent oil, price time series. 
and winters (October to March), as well as annual contracts.

Normally, contracts at NBP Hub are in pence sterling per therm. In this paper we convert the prices of all the time series to Euro per megawatt-hour ( $€ / \mathrm{MWh})$, the standard in Europe, allowing us for a better understanding of co-variations of prices. The appropriate conversion is 1 therm per $0.0293 \mathrm{MWh} \mathrm{ICIS}^{1}$, and the conversion of pence sterling to Euro is according to the daily exchange rate published by the ECB (European Central Bank) ${ }^{2}$.

There is no indigenous gas production in Greece and also there are no storage facilities (the LNG storage tanks are used exclusively for temporary LNG storage, the three entry points of natural gas to the National Natural Gas System (NNGS) of Greece are located at Sidirocastro, Greek Bulgarian pipeline, for the Russian gas, at Kipi, Greek-Turkish pipeline (BOTAS gas) and at the Revithoussa LNG terminal station. In Greece, the gas market is still organized on the basis of bilateral contracts between suppliers and eligible customers, so there is not any wholesale market yet. The Regulator (Regulatory Agency for Energy, RAE) of Greece published for the first time in 2011, the Weighted-Average Import Price (WAIP) of natural gas, on a monthly basis. This data on WAIP, considered together with the publication of data on daily prices of balancing gas, Daily Price of Balancing Gas (DPBG) or HTAE in Greek, on the Natural Gas TSO's (DESFA) internet site, has greatly facilitate current and potential market participants in understanding the prevailing gas price dynamics. The Figure 5

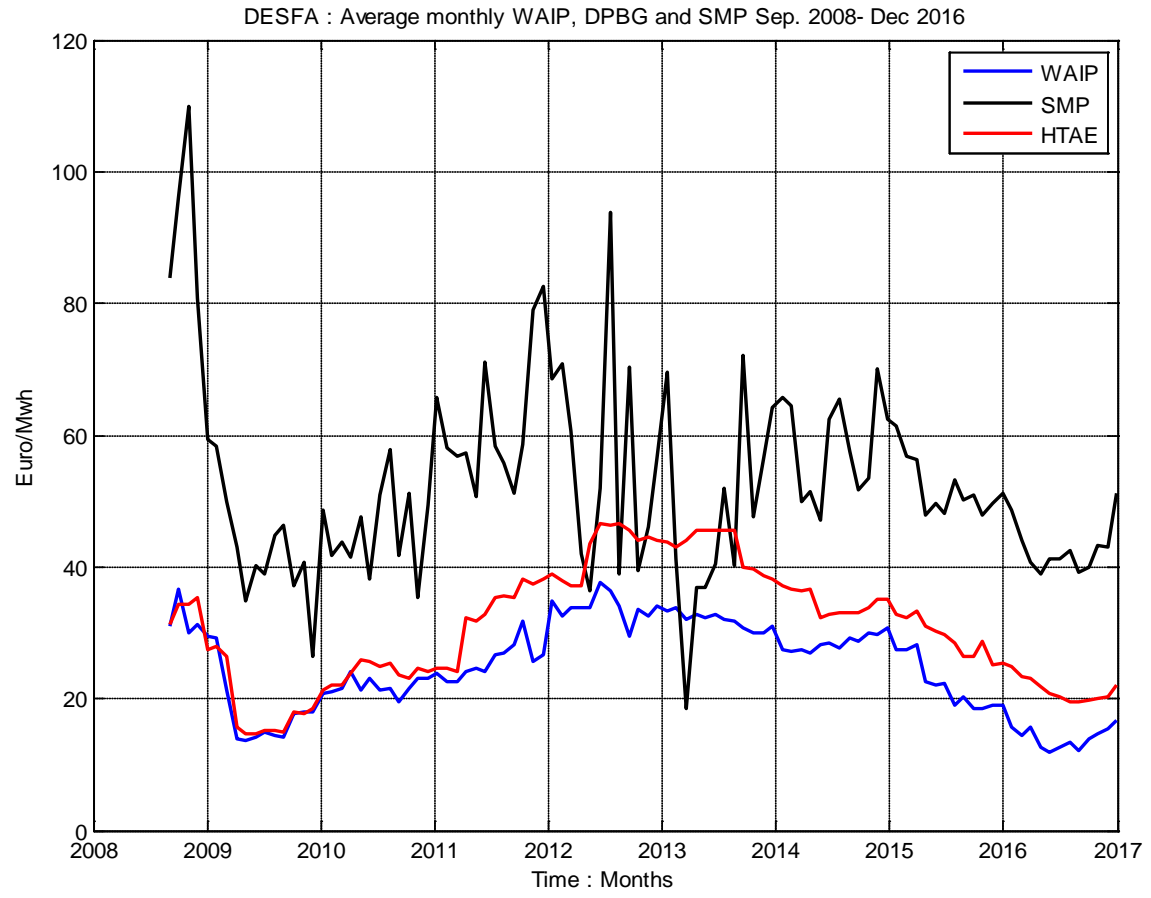

Figure 5. The monthly weighted average import prices of natural gas, the daily prices of balancing gas (HTAE) and SMP in the GEM.

${ }^{1}$ https://s3-eu-west-1.amazonaws.com/cjp-rbi-icis-compliance/wp-content/uploads/2013/12/ESGMMethodology-23-September-2013.pdf

${ }^{2}$ http://www.ecb.europa.eu/stats/exchange/eurofxref/html/eurofxref-graph-gbp.en.html. 
shows the monthly average System Marginal Price (SMP) of Greek Electricity Market (GEM), WAIP against the daily HTAE price for the same month (the daily HTAE price is kept constant over the entire month considered). Data are published on RAE's website ${ }^{3}$ and updated on a regular basis.

However we emphasize that our modeling is based on National's Balancing Point Spot prices as we have mentioned before, since (Figure 6) the average monthly dynamics of NGAS UK resembles DESFA's dynamics for the period of interest (2008-2014).

\subsection{The Greek Wholesale or System Marginal Price}

Greece's liberalized electricity market was established according to the European Directive 96/92/EC and consists of two separate markets: 1) the Wholesale Energy and Ancillary Services Market and 2) the Capacity Assurance Market. The Greek wholesale electricity market (GEM) is currently in a transitional period, during which the market structure evolves towards its final design, namely the European Target Model. The wholesale electricity market is a day ahead mandatory pool which is subject to inter-zonal transmission constraints, unit technical constraints, reserve requirements, the interconnection Net Transfer Capacities (NTCs) and in general all system constraints. More specifically, based on forecasted demand, generators' offers, suppliers' bids, power stations' availabilities, unpriced or must-run production (e.g., hydro power mandatory generation, cogeneration and RES outputs), schedules for interconnection as well as a

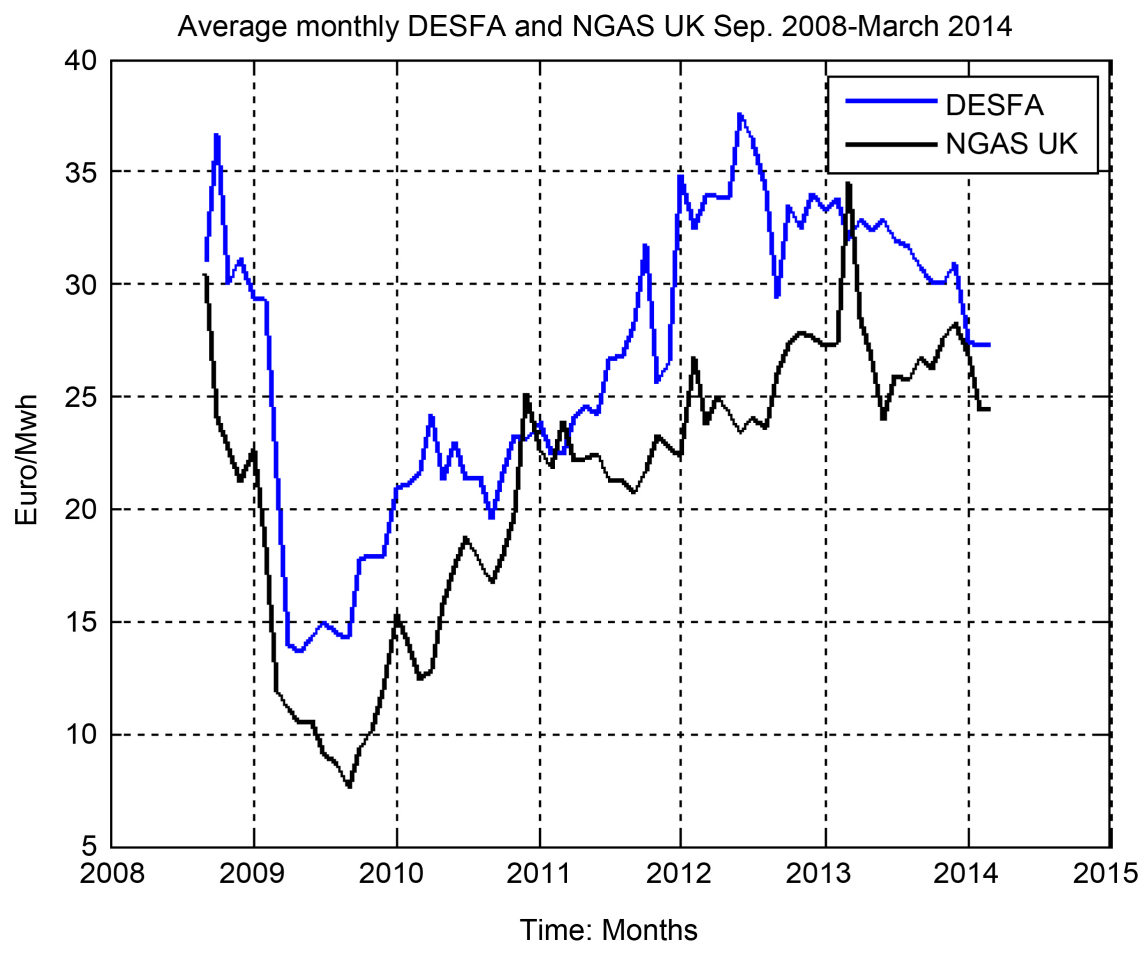

Figure 6. The average monthly DESFA and national balancing point price.

${ }^{3}$ http://www.rae.gr/site/en_US/categories_new/gas/market/wholesale_gr.csp 
number of transmission system's and power station's technical constraints, an optimization process is followed in order to dispatch the power plant with the lower cost, both for energy and ancillary services.

LAGIE (the independent market operator) (http://www.lagie.gr/) is responsible for the solution of the so-called Day Ahead (optimization) problem. This problem is formulated as a security constrained unit commitment problem, and its solution is considered to be the optimum state of the system at which the social welfare is maximized for all $24 \mathrm{~h}$ of the next day simultaneously. This is possible through matching the energy to be absorbed with the energy injected into the system, i.e., matching supply and demand (according to each unit's separate offers). The DA solution, therefore, determines the way of operation of each unit for each hour (dispatch period) of the dispatch day as well as the clearing price of the DA market's components (energy and reserves).

More specifically in this pool, market "agents" participating in the Energy component of the day-ahead (DA) market submit offers (bids) on a daily basis. Producers and importers submit energy offers with the limitation that the weighted average of the offer should be above the unit Minimum Average Variable Cost. On the contrary exporters and load representatives submit load declarations. The bids are in the form of a 10-step stepwise monotonically increasing (decreasing) function of pairs of prices $(€ / \mathrm{MWh})$ and quantities (MWh) for each of the $24 \mathrm{~h}$ period of the next day. A single price and quantity pair for each category of reserve energy (primary, secondary and tertiary) is also submitted by generators. Deadline for offer submission is at $12.00 \mathrm{pm}$ ("gate" closure time).

So, the DAS solution produces a 24 hour unit schedule and a unique price which is called the System's Marginal Price (SMP). The Dispatch Scheduling (DS) is used to define the time period between Day Ahead Schedule (DAS) and Real Time Dispatch (RTD) where the producers have the chance to change their declarations whenever has been a problem regarding the availability of their units. In the RTD the units are re-dispatched in real time in order to meet the actual demand. Finally in the IS stage an Ex Post Imbalance Pricing (EXPIP) is produced after the dispatch day which is based on the actual demand and unit availability. The capacity assurance market is a procedure where each load representative is assigned a capacity adequacy obligation and each producer issues capacity availability tickets for its net capacity. Actually this mechanism is facing any adequacies in capacity and is in place for the partial recovery of capital costs. The most expensive unit dispatched determines the uniform pricing in the day-ahead market. In case of congestion problems and as a motive for driving new capacity investment, zonal pricing is a solution, but at the moment this approach has not been activated. Physical delivery transactions are bounded within the pool although market agents may be entering into bilateral financial contracts that are not currently in existence. The offers of the generators are capped by an upper price level of $150 € / \mathrm{MWh}$. Physical Transmission Rights (PTR) are explicitly allocated via auctions. 
Not only the fundamentals but also the various Regulatory Market Reforms (RMRs), "imposed" by the Greek Regulatory for Energy (RAE), have a significant impact on the volatilities of energy and electric prices (RAE, 2009 to 2014 [38]), Kalantzis et al., 2012 [39]). The reforms took place on specific dates-milestones or Reference Days. The term Reference Day refers to the day that these reforms became active in the GEM. We describe here only the reforms made within the period of our analysis in this paper:

4th Reference Day (1.5.2008) (RMR5). Cost Recovery Mechanism, CRM, was considered by the Regulator a necessary step until the Imbalance Settlement Mechanism, ISM (scheduled for the 5th Reference Day). CRM states that if the SMP is lower than the marginal cost of generating Unit (plus 10\%), then the Unit will receive the difference as a compensation. The Regulator expected that this Reform would have no effect on SMP. CRM was aiming to ensure that generators will be compensated at least their marginal cost, in case they were ordered to operate. The Cost Recovery Mechanism was abolished on 30th June 2014.

RMR6. Regulatory Market Reform, RMR6 (RAE's Decision 1.1.2009), focused on the change of the ex-post SMP calculation methodology according to the unit commitment algorithm that considers all technical constraints of the units and the reserve requirements of the IPTO (ADMIE) expecting to lead to lower SMPs.

5th Reference Day (30.9.2010) (RMR7). Regulatory Market Reform, RMR7, initiated the mandatory day-ahead market model and introduced the Imbalances Settlement Mechanism retaining at the same time the SMP methodology allowing only the submission of demand declarations. RMR7 is referred to the adoption of an enhanced Unit commitment algorithm which co-optimizes energy as well as ancillary services. In this new mandatory, Day-Ahead market model incorporating, at the same time, an Imbalance settlement mechanism ${ }^{4}$, market clearance is now based on the non-priced demand declarations. Taking into account that the methodology for estimating SMP retained the same and the fact that usually the declared demands were underestimated, the effect of this reform expected to reduce SMP slightly.

RMR8. Regulatory Market Reform, RMR8 (Ministry of Finance Decision 1.9.2011), regards the decision of the Ministry of Finance (1.9.2011) to impose a new tax levy on natural gas, equal to $1.50 € / G J$ (applied also to electricity generation). As SMP was set, for the majority of trading periods, by Natural Gas fired Units, the resulted increased generation cost was expected to increase SMP (see Section 6.1 for comments).

RMR9. Regulatory Market Reform, RMR9 (1.7.2013), Abolition of the "Plus 10\% Rule". This rule was embedded in Cost Recovery Mechanism (CRM) and

${ }^{4}$ All imbalances-referring to the differences between the DAS (Day-Ahead-Schedule) and the real production or withdrawal of electricity-are settled through the Imbalance Settlement Mechanism. 
allowed for a $10 \%$ increase of the boundary for generators to be compensated for generating costs.

RMR10. Regulatory Market Reform, RMR10 (31.12.2013), Abolition of the "30\% Rule". The " $30 \%$ Rule" allows generators to offer $30 \%$ of their plant's capacity at a price below its minimum variable cost, as long as the total weighted average of their bids is still at or above their minimum variable cost. This caused the extended dispatch of gas plants, pushing the expenses on cost-recovery significantly high. The regulator expected no changes on the SMP through this reform, it was imposed merely to improve the performance of the initial market design.

Figure 7 depicts GEM's spot price (SMP) as well as the demand for the period of interest between 2007 and 2014.

\subsection{The Financial Data}

We have used the Athens Stock Exchange General Index (ase), denominated in Euro. In order to "capture" the independence-interaction of the Greek Stock market with the European financial market, especially during the financial crisis period (focusing on the European sovereign debt crisis in 2010), we have considered also the EURO STOXX 50 price index, in Euro, which covers 50 blue-chip stock from 12 European countries (Austria, Belgium, Finland, France, Germany, Greece, Ireland, Italy, Luxembourg, the Netherlands, Portugal and Spain). We choose this particular index, following Koch (2014) [16], because it is the basis for the EURO STOXX 50 Volatility Index (vstoxx), reflecting the market expectations of volatility. It measures the square root of implied variance over all
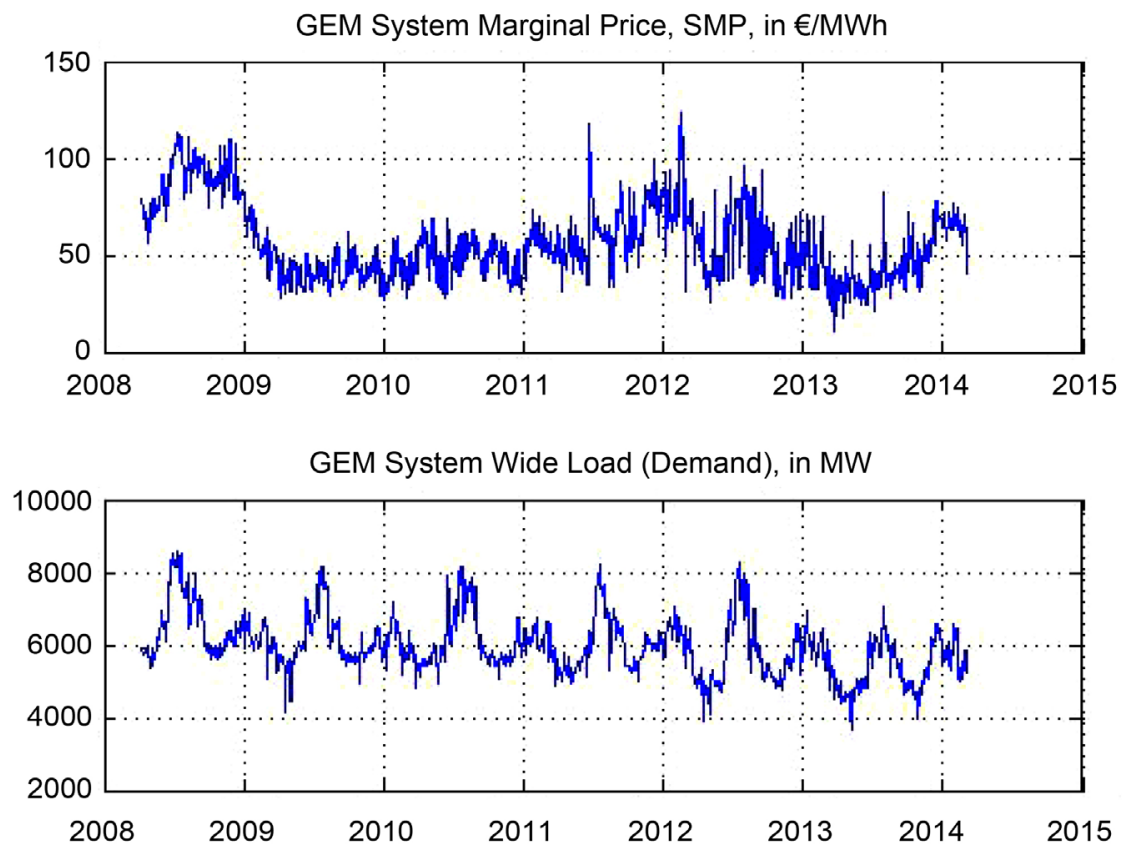

Figure 7. The wholesale (day-ahead, system marginal price, smp) and the system-wide load (demand) in the Greek electricity market (GEM) 10-Sep-2007 to 07-Mar-2014. 
EURO STOXX 50 options, for the next 30 days. Measuring the so-call investor's fear in case that it is larger than 30 indicates a large amount of volatility, reflecting the investor's uncertainty or fear.

For bond, we use the 10-year Greek Government bond index (gbonds) (a long-term index), instead of a short-term index, because monetary policy (especially during the Greek debt Crisis) is more likely to have a confounding impact on the later index.

We include also in the financial data set the stock price of the dominant player in GEM, the incubator Public Power Corporation (PPC). We consider that by analyzing the dynamic evolution of this stock we "capture" the various effects of regulatory policy and fundamental changes, exerted by monetary (macroeconomic) policies to fix the Greek Public Debt problem as well as European Energy Policies. Figure 8 shows the dynamics of the abovementioned indexes.

Table 1 summarizes and groups financial data set and energy commodities data set.

We have to mention here that for the purposes of this paper, we have included EUA into the group of Energy commodity assets, although there are arguments about this like the work of Kanamura (2010) [32] who argue that EUA is not a real commodity asset as those considered in the financial theory.

\section{Financial and Econometric Methodology}

\subsection{Using a VAR Modelling the Conditional Mean}

The equation or model of the Conditional mean or first moment is to detect and eliminate any serial correlation in the returns of price data. For a sequence

Athens Stock Exchange, ASE, index

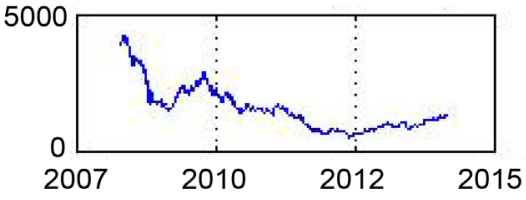

European Stock Vollatility index

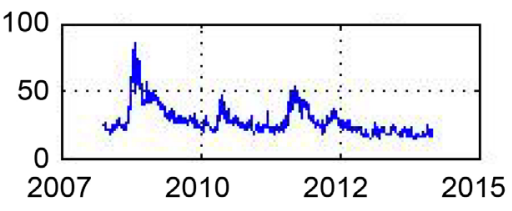

European Stock 50 index

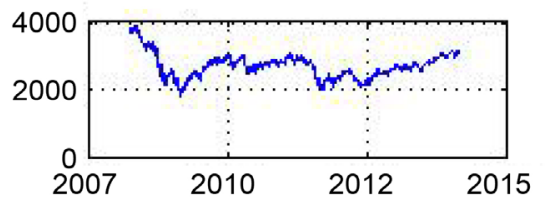

Public Power Coorporation Stock in €

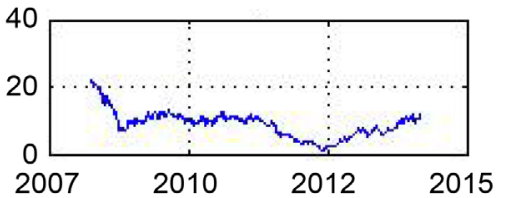

10-year Greek Gen. Goverment bonds yield

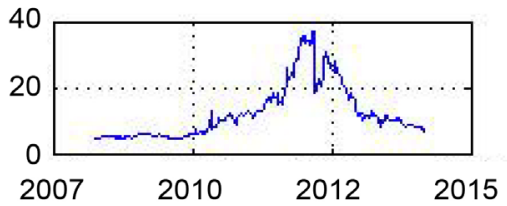

Figure 8. The financial data set's "assets", price (levels) time series for the period 8-Apr-2008 to 07-Mar-2014. 
Table 1. The data sets containing the variables employed in the DDC analysis (10-Sep-2007 to 07-Mar-2014).

\begin{tabular}{|c|c|c|}
\hline & Name & Description \\
\hline \multicolumn{3}{|r|}{ Financial Data Set } \\
\hline 1 & ase: & Athens Stock Exchange General Index \\
\hline 2 & stoxx: & European Stock 50 Index (Euro stoxx 50) \\
\hline 3 & vstoxx: & European Stock 50 Volatility Index (vstoxx) \\
\hline 4 & ppc: & Public Power Corporation (PPC) Stock price \\
\hline 5 & gbonds: & Greek Government 10 year Bond yield \\
\hline \multicolumn{3}{|c|}{ Energy Commodities Data Set } \\
\hline 1 & eua: & $\begin{array}{l}\text { European Union Allowance } \\
\text { (EU Emissions Trading Scheme): } € / \mathrm{tCO}_{2} \text { (Phase II) }\end{array}$ \\
\hline 2 & ngas: & Natural gas price, NBP, UK $€ / M W h$ \\
\hline 3 & brent: & Brent Oil price, $€ / \mathrm{bbl}$ \\
\hline 4 & Lignite price: & $\begin{array}{c}\text { Lignite Fuel Cost of a "typical" Lignite-fired } \\
\text { Power plant }(€ / M W h)\end{array}$ \\
\hline \multicolumn{3}{|c|}{ Power (Electricity) Data Set } \\
\hline 1 & smp: & $\begin{array}{l}\text { Greek Electricity Market wholesale or System } \\
\text { Marginal Price (ex-ante) }(€ / M W h)\end{array}$ \\
\hline 2 & load: & Electricity load (Mw) (ex-post) \\
\hline
\end{tabular}

of random variables $\left\{X_{t}\right\}$ the conditional mean (or conditional expectation), given its past values is defined as: $E\left[X \mid X_{t-1}, X_{t-2}, \cdots, X_{t-j}\right]$. As we will see in Section 5.1, by applying the Ljung-Box test statistics, there is strong evidence of significant serial correlation in the returns. Vector Autoregression (VAR) of lag order $p$ is used in this paper to estimate the first moment.

Let $\boldsymbol{r}_{t}$ symbolizes a $k \times 1$ vector of returns at time $t, \boldsymbol{r}_{t}=\left\{r_{i, t}\right\}$, where $r_{i, t}$ is the daily $\log$ returns, for $i=1, \cdots, k$. The $\operatorname{VAR}(p)$ model is written as

$$
\begin{aligned}
& \boldsymbol{r}_{t}=\boldsymbol{\Phi}_{0}+\sum_{j=1}^{p} \boldsymbol{\Phi}_{j} \boldsymbol{r}_{t-j}+\boldsymbol{\varepsilon}_{t} \\
& \text { or } \boldsymbol{r}_{t}=\boldsymbol{\Phi}_{0}+\boldsymbol{\Phi}_{1} \boldsymbol{r}_{t-1}+\cdots+\boldsymbol{\Phi}_{p} \boldsymbol{r}_{t-p}+\boldsymbol{\varepsilon}_{t}
\end{aligned}
$$

where $\Phi_{0}$ is a $k \times 1$ vector of constants, $\Phi_{j} k \times k$ matrix of coefficients and $\varepsilon_{t}$ a $k \times 1$ vector of residuals. The "optimum" lag length $\mathrm{p}$ of the $\operatorname{VAR}(\mathrm{p})$ can be found by minimizing the Akaike Information Criterion (AIC). The specification then of the "best" model, based on AIC, is accepted if the residual "pass" successfully a number of diagnostic tests (e.g. checking for remaining serial correlation).

As an example, let $k=3$, a trivariate model $\boldsymbol{r}=(\text { ase, stoxx, vstoxx })^{\prime}$ and let $p=2$, lags, then (A) becomes 


$$
\begin{aligned}
{\left[\begin{array}{c}
\text { ase }, t \\
\text { stoxx }, t \\
\text { vstoxx }, t
\end{array}\right]=} & {\left[\begin{array}{l}
\Phi_{1,0} \\
\Phi_{2,0} \\
\Phi_{3,0}
\end{array}\right]+\left[\begin{array}{lll}
\Phi_{11,1} & \Phi_{12,1} & \Phi_{13,1} \\
\Phi_{21,1} & \Phi_{22,1} & \Phi_{23,1} \\
\Phi_{31,1} & \Phi_{32,1} & \Phi_{33,1}
\end{array}\right] \cdot\left[\begin{array}{c}
\text { ase }, t-1 \\
\text { stoxx }, t-1 \\
\text { vstoxx }, t-1
\end{array}\right] } \\
& +\left[\begin{array}{lll}
\Phi_{11,2} & \Phi_{12,2} & \Phi_{13,2} \\
\Phi_{21,2} & \Phi_{22,2} & \Phi_{23,2} \\
\Phi_{31,2} & \Phi_{32,2} & \Phi_{33,2}
\end{array}\right] \cdot\left[\begin{array}{c}
\text { ase }, t-2 \\
\text { stoxx }, t-2 \\
\text { vstoxx }, t-2
\end{array}\right]+\left[\begin{array}{c}
\varepsilon_{\text {ase }, t} \\
\varepsilon_{\text {stoxx }, t} \\
\varepsilon_{\text {vstoxx }, t}
\end{array}\right]
\end{aligned}
$$

Serially uncorrelated residuals are generated by a well-specified model for the first moment of the returns. However, heteroskedasticity (the time-varying variance of the residuals) will remain in the returns, as it is frequently the case in Energy and financial markets. This feature and the excess kurtosis in the returns call for the GARCH-type estimation approach (Engle, 1982 [40], Bollerslev, 1986 [41]). The GARCH model incorporates the heteroskedasticity characteristic of the data. The works of Chevallier et al. (2009) [10], Benz and Truck (2009) [42], Mansanet-Bataller and Soriano (2009) [6] refer to the application of this type of model in Carbon (EUA) and energy market time series.

Let that the mean of a return time series follows an autoregressive of order $p$, $\operatorname{AR}(p)$, specification

$$
r_{i, t}=a_{o}+\sum_{j=1}^{p} a_{j} r_{i, t-j}+\varepsilon_{i, t}
$$

where $r_{i, t}$ is the daily $\log$ returns of $K$ time series for $i=1, \cdots, K, \varepsilon_{i, t}$ is the residual of series $i$ and $a_{o}$ the drift term.

Suppose that $F_{t-1}$ is the set of all available information about the process, up to the time $t-1$, then the conditional variance of the residual $\varepsilon_{i, t}$ is $\sigma_{i, t}^{2}$, so $\varepsilon_{i, t} \mid F_{t-1} \sim N\left(0, \sigma_{i, t}^{2}\right)$ or $\varepsilon_{i, t}=\sigma_{i, t} n_{t}$ where $n_{t} \sim N I D(0,1)$.

This $\varepsilon_{i, t}$ residual is fitted in the GARCH-type models, described below, to capture the dynamics of the conditional variance.

Let the evolution of the conditional variance in the generic univariate process for each asset, is written as

$$
\sigma_{\delta}^{2}=\omega+\sum_{p=1}^{P} \alpha_{p}\left|\varepsilon_{t-p}\right|^{\delta}+\sum_{o=1}^{O} \gamma_{o}\left|\varepsilon_{t-o}\right|^{\delta} I\left[\varepsilon_{t-o}<o\right]+\sum_{q=1}^{Q} \beta_{q} \sigma_{t-q}^{\delta}
$$

where $\delta$ is either 1 for threshold ARCH also known as AVGARCH, ZARCH (Taylor, 1986 [43], Zakoian, 1994 [44]) or 2 for ARCH, GARCH or GJR-GARCH models (Glosten et al., 1993 [45]). In this paper we consider the case of $\delta=2$ and particularly the case $\operatorname{GJR}-\operatorname{GARCH}(P, O, Q)$. In fact, we fit our data in a GJR-GARCH $(1,1,1)$ model, the dynamics of which is written as

$$
\sigma_{t}^{2}=\omega+\alpha_{1} \varepsilon_{t-1}^{2}+\gamma_{1} \varepsilon_{t-1}^{2} I_{\left[\varepsilon_{t-1}<0\right]}+\beta_{1} \sigma_{t-1}^{2}
$$

where $I_{\left[\varepsilon_{t-1}<0\right]}$ is an indicator function that takes the value 1 if $\varepsilon_{t-1}<0$ and 0 otherwise. This function takes care of the asymmetries of the impact on volatility the returns may have due to "good" or "bad" news. The parameters must be such that $\omega>0, \alpha_{1} \geq 0, \alpha_{1}+\gamma \geq 0$ and $\beta_{1} \geq 0$, and for the covariance to be 
stationary, $\alpha_{1}+\frac{1}{2} \gamma_{1}+\beta_{1}<1$ (mean reverting model). In case $\alpha_{1}+\beta_{1}=1$ we have an integrated model.

In estimating $h_{i t}$ from univariate volatility models, the BIC Schwartz Information Criterion is use to select suitable candidate models that capture the stylized facts of the asset return.

\subsection{Constant Conditional Correlation (CCC) and Dynamic Conditional Correlation, DCC, Models}

A multivariate $\operatorname{GARCH}(P, O, Q)$ is a natural extension of the univariate model, and allows for the time-varying correlations between two series, in addition to their conditional variances. To generate a vector of residuals (hopefully serially uncorrelated) we could use a Vector Autoregression model, $\operatorname{VAR}(p)$, to model the mean of a $11 \times 1$ vector consisting of the members of the financial, energy and power group of data set, given in Table 1 . The model produces the following vector of residuals

$$
\varepsilon_{t}=\left(\varepsilon_{\text {ase }, t}, \varepsilon_{\text {stoxx }, t}, \varepsilon_{\text {vstoxx }, t}, \varepsilon_{\text {ppc }, t}, \varepsilon_{\text {gbonds }, t}, \varepsilon_{\text {eua }, t}, \varepsilon_{\text {ngas }, t}, \varepsilon_{\text {brent }, t}, \varepsilon_{\text {smp }, t},, \varepsilon_{\text {lignite }, t}, \varepsilon_{\text {load }, t}\right)^{\prime}
$$

We also suppose that the underlying distribution of returns follows a conditional multivariate normal process, therefore we can write $\varepsilon_{t} \mid F_{t-1} \sim N\left(\mathbf{0}, H_{t}\right)$, where $F_{t-1}$ is a filtration i.e. an information set about the time series up to the time step $t-1$. Thus, the $\varepsilon_{t}$ is conditionally heteroskedastic, which means that $\boldsymbol{\varepsilon}_{t}=\sqrt{H_{t}} \cdot \boldsymbol{n}_{t}$, where $\boldsymbol{n}_{t} \sim N(\mathbf{0}, I)$ an iid error process.

For modelling $H_{t}$ a number of specifications has been suggested, the most commonly mentioned is the generic VECH-model, developed by Bollerslev et al. (1986) [41], the CCC-model (Constant Conditional Correlation) also by Bollerslev (1990) [46] and the BEKK-model by Engle and Kroner (1995) [2]. A detailed survey on multivariate GARCH models is provided by Silvennoinen and Tersvirta (2007) [47].

In this paper will apply the parsimonious Dynamic Conditional Correlation (DCC) approach, developed by Engle (2002) [48] and Engle and Sheppard (2001) [49]. This model is actually a natural extension of the CCC-model, giving the opportunity for a two-stage estimation of the dynamic evolution of conditional correlations between, for example, two commodities. In the first stage of the procedure, standardized residuals are generated by univariate GARCH models fitted on the data of the individual time series. In the second stage the correlation process is estimated.

According to the work of Engle and Sheppard (2001) [49], the conditional covariance matrix $H_{t}$ is written as follows

$$
H_{t}=D_{t} R_{t} D_{t}
$$

where $D_{t}$ a $k \times k$ diagonal matrix with elements $\sqrt{\sigma_{i, t}^{2}}$ on the ith diagonal representing the time-varying standard deviations which are generated by the GARCH models fitted on each residual series, as the ones given in Equation (7). 
$R_{t}$ is the time-varying conditional correlation matrix. In the case of CCC-model we have:

Model 1: $H_{t}=D_{t} R D_{t}$

$$
R=\left(\rho_{i j}\right)
$$

where $R=$ Constant Conditional Correlation. The assumption that conditional correlations are constant is unrealistic in particular applications, although the estimation of CCC parameters is simpler. We use CCC hare as a benchmark for testing the consistency of correlations (see Table 6 below).

The log-likelihood is our case, for the vector $\theta$ of parameters is given by

$$
L(\theta)=-\frac{1}{2} \sum_{t=1}^{T}\left(m \log (2 \pi)+2 \log \left(\left|D_{t}\right|\right)+\log \left(\left|R_{t}\right|\right)+\xi_{t}^{\prime} R_{t}^{-1} \xi_{t}\right)
$$

where $\boldsymbol{\xi}_{t} \sim N\left(\mathbf{0}, R_{t}\right)$ the standardized residuals, $\xi_{t}=\frac{\boldsymbol{\varepsilon}_{t}}{D_{t}}$.

In case that the conditional distribution of $\boldsymbol{\varepsilon}_{t}$ is not normal, Equation (9) is the Quasi-likelihood function. The dynamic correlation specification suggested by Engle and Sheppard (2001) [49] is:

$$
Q_{t}=\left(1-\sum_{j=1}^{P} \alpha_{j}-\sum_{j=1}^{Q} \beta_{j}\right) \bar{Q}+\sum_{j=1}^{P} \alpha_{j}\left(\xi_{t-j} \xi_{t-j}^{\prime}\right)+\sum_{j=1}^{Q} \beta_{j} Q_{t-j}
$$

where $\bar{Q}$ is the $k \times k$ unconditional covariance matrix of the standardized residuals, generated from the first stage of the process. The extent to which $\xi_{t}$ affect the dynamics of the correlation is captured by the $\alpha_{j}$, while $\beta_{j}$ is a parameter measuring the decay in dynamics. If we plug $\alpha_{j}=\beta_{j}=0$ into (11), the CCC model of Bollerslev (1990) [46] is obtained. The lag-lengths of residuals and decay are expressed by $P$ and $Q$ (not to be confused with those in Equation (6)). Finally, the dynamic conditional correlation is written

$$
R_{t}=Q_{t}^{*-1} Q_{t} Q_{t}^{*-1}
$$

where $Q_{t}^{*}$ is a diagonal matrix $(k \times k)$ consisting of the square root of the diagonal elements of $Q_{t}$. Furthermore, the conditional covariance matrix $R_{t}$ of the residuals generated by $\operatorname{VAR}(p)$, is obtained by standardizing these residuals by the conditional variances, so a typical element of $R_{t}$ is

$$
\rho_{i, j, t}=\frac{q_{i, j, t}}{\sqrt{q_{i, i, t} q_{j, j, t}}}
$$

In the framework of this paper estimation, the indices range as

$$
i, j=\text { ase, stoxx, vstoxx, ppc, eua, ngas, brent, smp, load, lignite }
$$

By letting $P=Q=1$ in Equation (11) we obtained our DCC model 2 specification:

Model 2: $Q_{t}=(1-\alpha-\beta) \bar{Q}+\alpha\left(\xi_{t-1} \xi_{t-1}^{\prime}\right)+\beta Q_{t-1}$

The matrix $Q_{t}$ is a symmetric positive matrix, $\alpha+\beta<1$, and $\alpha$ is the news coefficient and $\beta$ is the decay coefficient. According to Aielli (2011) 
[50], typical values of the dynamic parameters $\alpha, \alpha+\beta$ are $\alpha+\beta>0.80$ and $\alpha \leq 0.04$ while in financial application, in particular, $\alpha+\beta \geq 0.96$ and $\alpha \leq 0.04 . \bar{Q}=E\left[\xi_{t} \xi_{t}^{\prime}\right]$ is the unconditional correlation (the unconditional variance matrix of the standardize residuals. A typical element of the correlation matrix $R_{t}$, regarding the interaction, for example, between ase index and ppc stock price is

$$
\rho_{a s e, p p c, t}=\frac{q_{a s e, p p c, t}}{\sqrt{q_{a s e, p p c, t} q_{a s e, p p c, t}}}
$$

Therefore, by using model 2 above, we have

$$
\begin{gathered}
q_{a s e, p p c, t}=(1-\alpha-\beta) \bar{q}_{a s e, p p c}+\alpha\left(\xi_{a s e, t-1} \xi_{p p c, t-1}^{\prime}\right)+\beta q_{a s e, p p c, t-1} \\
q_{a s e, t}=(1-\alpha-\beta) \bar{q}_{a s e}+\alpha\left(\xi_{a s e, t-1}^{2}\right)+\beta q_{a s e, t-1} \\
q_{p p c, t}=(1-\alpha-\beta) \bar{q}_{p p c}+\alpha\left(\xi_{p p c, t-1}^{2}\right)+\beta q_{p p c, t-1}
\end{gathered}
$$

Model 1 will be our basic reference model. This scalar DCC specification is the most parsimonious one because of the assumption that all commodities correlations "obey" the same ARMA $(\mathrm{P}, \mathrm{Q})$ type specification, which means that they are all governed by the same coefficients $\alpha$ and $\beta$. The above assumption might be a valid one, in the case of similar commodities (or "assets" in general), belonging in same asset category or class. However, in our case, our "assets" belong to different categories, namely financial, energy and power; therefore it is a reasonable assumption that these markets exhibit "asset" specific correlation sensitivities. To face this dissimilarity in asset's class, a generalization of the DCC model has been suggested, incorporating also the impact of any asymmetries on the correlation dynamics. It is known that in a Markov Switching Model (MSM) or in a Threshold Autoregressive Model (TARM), the conditional correlations are allowed to have different evolutionary dynamics. Instead this is not the case for DCC model in which the correlations follow the same dynamics. This is a limitation of the DCC. For example, if the data exhibit structural breaks, DCC model can give misleading conclusions. Another limitation of DCC is that it does not work reliably for large number of assets. Cappielo et al. (2006) [51] have developed a number of various asymmetric multivariate GARCH models to capture the asymmetries. For an in depth description of the "mathematical" properties, its limitation and inconsistencies in DCC model, Aielli (2011) [50] provides an excellent work.

\subsection{The Asymmetric Generalized DCC Model}

Engle (2002) [48] propose a Generalized Dynamic Conditional Correlation (G-DCC) in order to tackle the correlation across asset categories, a flexible model allowing for asset specific correlation parameters. The model is written as

Model 3: $Q_{t}=\left(\bar{Q}-A^{\prime} \bar{Q} A-B^{\prime} \bar{Q} B\right)+A^{\prime} \xi_{t-1} \xi_{t-1}^{\prime} A+B^{\prime} Q_{t-1} B$

where $A$ and $B$ are $k \times k$ diagonal matrices of the parameters, $A=\left\{\alpha_{i i}\right\}$, 
$B=\left\{\beta_{i i}\right\}$.

The positive definiteness requirement is satisfied by $\alpha_{i i}+\beta_{i i}<1$ and $\alpha_{i i}, \beta_{i i} \geq 0, \forall i, j$. The above specification tackles the dissimilarity of asset problem by allowing for a high degree of dissimilarity in correlations.

The advantage of G-DCC over the simple scalar DCC is that it can generate a variety of correlation patterns. The coefficients $\alpha_{i i}$ can be considered for measuring the sensitivity of the correlation of asset $i$ with other assets to correlation residuals (Hafner and Frances, 2003) [52]. High values for $\alpha_{i i}$ in combination with low values for $\beta_{i i}$ result in almost horizontal, very flat correlations of asset $i$ with any other asset in the specification. Instead, low values for $\alpha_{i i}$ combined with high values for $\beta_{i i}$ produce very fluctuating correlations.

Cappielo et al. (2006) [51] proposes a further generalization, the AG-DCC (Asymmetric Generalized DCC) model 4 that actually nests model 4, written as

Model 4: $Q_{t}=\left(\bar{Q}-A^{\prime} \bar{Q} A-B^{\prime} \bar{Q} B-G^{\prime} \bar{N} G\right)+A^{\prime} \xi_{t-1} \xi_{t-1}^{\prime} A+B^{\prime} Q_{t-1} B+G^{\prime} \boldsymbol{n}_{t-1} \boldsymbol{n}_{t-1}^{\prime} G$

where $G$ is a $k \times k$ diagonal matrix of parameters, $G=\left\{g_{i i}\right\}, \boldsymbol{n}_{t}=\left\{n_{i, t}\right\}$ a $k \times 1$ vector with $n_{i, t}=\min \left(\xi_{t}, 0\right), \bar{N}$ is a $k \times k$ matrix of constants, $\bar{N}=T^{-1} \sum_{t=1}^{T} n_{t} n_{t}^{\prime}$.

Similarly as in model 3 , the positive definiteness requirement is satisfied by $\alpha_{i i}+\beta_{i i}+n_{i} k<1$ and $\alpha_{i i}, \beta_{i i}, n_{i} \geq 0$, for $i=1, \cdots, k$ where $k$ is the maximum eigenvalue of $\sqrt{\bar{Q}} \bar{N} \sqrt{\bar{Q}}$ (Cappielo et al., 2006) [51].

Model 4 is further extended to include control ("exogenous") variables Vargas (2008) [53] proposed the AG-DCC-X model and it is this model used by Koening (2011) [20] to test the hypothesis of the effect of static merit order regimes on correlation between input fuels, carbon emission and electricity prices. We do not consider the model in this paper but we have included for the completeness of our review.

By using that $A^{\prime} * A=A^{2}, B^{\prime} * B=B^{2}$ etc., little algebra transforms model 3 into the following form

$$
Q_{t}=\left(1-A^{2}-B^{2}\right) \bar{Q}+A^{2} \boldsymbol{\xi}_{t-1} \xi_{t-1}^{\prime}+B^{2} Q_{t-1}+G^{2}\left(\boldsymbol{n}_{t-1} \boldsymbol{n}_{t-1}^{\prime}-\bar{N}\right)
$$

\section{Empirical Findings}

\subsection{Data Tests and Applied Methodology}

In this subsection we present the empirical findings, while in Section 5.2 we comment on these findings in details. Table 2 provides the summary statistics of price levels and of the electricity load (demand). The correlation matrix of all variables (raw data) is shown in Table 3. While Table 4 provides summary statistics of log returns of the variables considered.

The correlation matrix between levels of variables yields mostly "rational" results as expected. Financial assets in particular have moderately strong positive (between indexes and stocks) and negative (between bonds and stocks) correlations, and mostly low degree of correlations with energy commodities and electricity. 
P. G. Papaioannou et al.

Table 2. Summary statistics of price (levels) (8-Apr-2008 to 07-Mar-2014).

\begin{tabular}{|c|c|c|c|c|c|c|c|c|c|c|c|c|}
\hline \multicolumn{2}{|c|}{$\begin{array}{l}\text { Price (level) } \\
\text { Series }\end{array}$} & ase & stoxx & vstoxx & ppc & gbonds & eua & ngas & brent & lignite & smp & load \\
\hline \multicolumn{2}{|c|}{ Observations } & 2160 & 2160 & 2160 & 2160 & 2160 & 2160 & 2160 & 2160 & 2160 & 2160 & 2160 \\
\hline \multicolumn{2}{|c|}{ Mean } & 1561.76 & 2703.01 & 27.40 & 8.81 & 12.19 & 12.16 & 21.71 & 95.24 & 33.69 & 56.05 & 5998.79 \\
\hline \multicolumn{2}{|c|}{ Median } & 1437.66 & 2710.37 & 24.40 & 9.55 & 10.15 & 12.90 & 23.50 & 105.78 & 35.10 & 52.49 & 5907.71 \\
\hline \multicolumn{2}{|c|}{ Maximum } & 4303.77 & 3882.28 & 85.44 & 21.92 & 37.10 & 31.71 & 36.91 & 143.95 & 48.53 & 123.77 & 8555.83 \\
\hline \multicolumn{2}{|c|}{ Minimum } & 476.36 & 1809.98 & 13.82 & 1.15 & 4.42 & 2.70 & 7.08 & 34.45 & 21.98 & 10.24 & 3684.54 \\
\hline \multicolumn{2}{|c|}{ Std. Dev. } & 837.03 & 359.95 & 10.42 & 3.81 & 8.09 & 6.24 & 6.26 & 23.59 & 5.77 & 19.27 & 801.24 \\
\hline \multicolumn{2}{|c|}{ Skewness } & 1.35 & 0.60 & 1.86 & 0.44 & 1.33 & 0.79 & -0.61 & -0.68 & -0.20 & 0.74 & 0.63 \\
\hline \multicolumn{2}{|c|}{ Kurtosis } & 3.98 & 3.89 & 7.50 & 4.01 & 3.95 & 3.40 & 2.36 & 2.54 & 2.76 & 3.04 & 3.48 \\
\hline & $\mathrm{h}$ & 1 & 1 & 1 & 1 & 1 & 1 & 1 & 1 & 1 & 1 & 1 \\
\hline \multirow[t]{3}{*}{ JB } & $p$-value & 0.00 & 0.00 & 0.00 & 0.00 & 0.00 & 0.00 & 0.00 & 0.00 & 0.00 & 0.00 & 0.00 \\
\hline & Stat. & 669.95 & 198.92 & 3069.40 & 163.04 & 714.96 & 240.4 & 170.20 & 183.73 & 19.27 & 198.71 & 162.19 \\
\hline & $\mathrm{h}$ & 1 & 0 & 1 & 0 & 1 & 0 & 0 & 0 & 1 & 0 & 0 \\
\hline \multirow[t]{3}{*}{$\mathrm{ADF}$} & $p$-value & 0.00 & 0.34 & 0.14 & 0.05 & 0.38 & 0.03 & 0.46 & 0.55 & 0.84 & 0.00 & 0.34 \\
\hline & Stat. & -3.30 & -1.45 & -1.97 & -0.74 & -2.10 & -0.53 & -0.28 & 0.59 & -3.31 & -0.86 & 0.59 \\
\hline & $\mathrm{h}$ & 1 & 0 & 1 & 0 & 1 & 0 & 0 & 0 & 1 & 0 & 0.00 \\
\hline \multirow[t]{2}{*}{ PP } & $p$-value & 0.00 & 0.34 & 0.14 & 0.05 & 0.38 & 0.03 & 0.46 & 0.55 & 0.84 & 0.00 & 0.34 \\
\hline & Stat. & -3.30 & -0.85 & -1.45 & -1.97 & -0.74 & -2.10 & -0.53 & -0.28 & 0.59 & -3.31 & -0.86 \\
\hline
\end{tabular}

Interpretation of the Boolean variable $\mathrm{h}: \mathrm{h}=1$ the null hypothesis of the test is rejected, $\mathrm{h}=0$ fail to reject the null hypothesis of the test. JB test the null hypothesis of normality, ADF and PP test the null hypothesis of unit root.

Table 3. Correlation matrix between levels of variables considered in this study.

\begin{tabular}{|c|c|c|c|c|c|c|c|c|c|c|c|}
\hline & “ase" & “stoxx" & "vstoxx" & “ppc" & "gbonds" & “eua” & "ngUK" & "brent" & "lignite" & “smp" & "load" \\
\hline “ase" & 1 & 0.6504 & 0.0851 & 0.8790 & -0.6797 & 0.8527 & -0.2440 & -0.2276 & -0.7683 & 0.2562 & 0.3134 \\
\hline “stoxx" & - & 1 & -0.5302 & 0.7323 & -0.4838 & 0.4718 & 0.2077 & 0.3467 & -0.1803 & 0.1619 & 0.0633 \\
\hline "vstoxx" & - & - & 1 & -0.0913 & -0.0307 & 0.2897 & -0.1447 & -0.5587 & -0.4267 & 0.3028 & 0.1319 \\
\hline "ppc" & - & - & - & 1 & -0.7478 & 0.7086 & -0.2340 & -0.1821 & -0.4764 & 0.1143 & 0.2468 \\
\hline "gbonds" & - & - & - & - & 1 & -0.4271 & 0.2796 & 0.4740 & 0.3777 & 0.1455 & -0.0716 \\
\hline “eua" & - & - & - & - & - & 1 & -0.1364 & -0.1550 & -0.8159 & 0.4379 & 0.4122 \\
\hline “ngUK” & - & - & - & - & - & - & 1 & 0.6567 & 0.2481 & 0.3734 & -0.1327 \\
\hline "brent" & - & - & - & - & - & - & - & 1 & 0.3749 & 0.1706 & -0.0773 \\
\hline "lignite" & - & - & - & - & - & - & - & - & 1 & -0.3414 & -0.3944 \\
\hline "smp" & - & - & - & - & - & - & - & - & - & 1 & 0.4675 \\
\hline "loadep" & - & - & - & - & - & - & - & - & - & - & 1 \\
\hline
\end{tabular}


Table 4. Daily log returns summary statistics (08-Apr-2007 to 07-Mar-2014).

\begin{tabular}{|c|c|c|c|c|c|c|c|c|c|c|c|c|}
\hline \multicolumn{2}{|c|}{ Log Return Series } & ase & stoxx & vstoxx & $\mathrm{ppc}$ & gbonds & eua & ngas & brent & lignite & $\mathrm{smp}$ & load \\
\hline \multicolumn{13}{|c|}{ Panel A: Descriptive statistics } \\
\hline \multicolumn{2}{|c|}{ Observations } & 2159 & 2159 & 2159 & 2159 & 2159 & 2159 & 2159 & 2159 & 2159 & 2159 & 2159 \\
\hline \multicolumn{2}{|c|}{ Mean } & 0.00 & 0.00 & 0.00 & 0.00 & 0.00 & 0.00 & 0.00 & 0.00 & 0.00 & 0.00 & 0.00 \\
\hline \multicolumn{2}{|c|}{ Median } & 0 & 0 & 0 & 0 & 0 & 0 & 0 & 0 & 0 & 0 & 0 \\
\hline \multicolumn{2}{|c|}{ Maximum } & 0.13 & 0.10 & 0.33 & 0.22 & 0.14 & 0.24 & 0.36 & 0.18 & 0.29 & 1.02 & 0.20 \\
\hline \multicolumn{2}{|c|}{ Minimum } & -0.10 & -0.08 & -0.27 & -0.25 & -0.68 & -0.43 & -0.11 & -0.17 & -0.25 & -0.87 & -0.25 \\
\hline \multicolumn{2}{|c|}{ Std. Dev. } & 0.02 & 0.01 & 0.05 & 0.03 & 0.02 & 0.03 & 0.02 & 0.02 & 0.02 & 0.16 & 0.04 \\
\hline \multicolumn{2}{|c|}{ Skewness } & 0.06 & 0.12 & 0.86 & -0.18 & -12.55 & -1.21 & 3.29 & 0.02 & 4.21 & 0.03 & -0.63 \\
\hline \multicolumn{2}{|c|}{ Kurtosis } & 7.31 & 11.32 & 8.09 & 10.70 & 327.73 & 34.44 & 46.55 & 16.49 & 103.69 & 8.82 & 10.22 \\
\hline & $\mathrm{h}$ & 1 & 1 & 1 & 1 & 1 & 1 & 1 & 1 & 1 & 1 & 1.00 \\
\hline \multirow{2}{*}{$\begin{array}{c}\text { JB } \\
(p \text {-value })\end{array}$} & $p$-value & 0.00 & 0.00 & 0.00 & 0.00 & 0.00 & 0.00 & 0.00 & 0.00 & 0.00 & 0.00 & 0.00 \\
\hline & Stat. & 1670 & 6231.9 & 2591.4 & 5342.8 & 9543009.1 & 89462.8 & 174476.26 & 16361.3 & 918408.54 & 3051.87 & 4831.9 \\
\hline \multicolumn{13}{|c|}{ Panel B: Stationarity } \\
\hline \multirow{4}{*}{$\mathrm{ADF}$} & h1 & 1 & 1 & 1 & 1 & 1 & 1 & 1 & 1 & 1 & 1 & 1 \\
\hline & $p$-value & 0.000 & 0.000 & 0.000 & 0.00 & 0.00 & 0.00 & 0.00 & 0.00 & 0.00 & 0.00 & 0.00 \\
\hline & Stat. & -43.78 & -45.64 & -46.43 & -42.92 & -42.06 & -44.7 & -47.17 & -58.80 & -62.95 & -52.21 & -58.80 \\
\hline & $\mathrm{h}$ & 1 & 1 & 1 & 1 & 1 & 1 & 1 & 1 & 1 & 1 & 0.00 \\
\hline \multirow[t]{2}{*}{ PP } & $p$-value & 0.000 & 0.00 & 0.00 & 0.00 & 0.00 & 0.00 & 0.00 & 0.00 & 0.00 & 0.00 & 0.00 \\
\hline & Stat. & -43.78 & -45.64 & -46.43 & -42.92 & -42.06 & -44.7 & -46.43 & -47.17 & -58.80 & -62.95 & -52.21 \\
\hline \multicolumn{13}{|c|}{ Panel C: Serial Correlation. ARCH tests } \\
\hline \multirow{4}{*}{$\mathrm{Q}(20)$} & $\mathrm{h}$ & 0 & 1 & 1 & 1 & 1 & 1 & 1 & 1 & 1 & 1 & 1 \\
\hline & $p$-value & 0.06 & 0.00 & 0.00 & 0.00 & 0.00 & 0.00 & 0.00 & 0.00 & 0.00 & 0.00 & 0.00 \\
\hline & Stat. & 30.7 & 56.53 & 52.55 & 52.41 & 58.22 & 67.50 & 53.44 & 41.76 & 187.97 & 243.84 & 162.24 \\
\hline & $\mathrm{h}$ & 1 & 1 & 1 & 1 & 0 & 1 & 0 & 1 & 1 & 1 & 1 \\
\hline \multirow[t]{3}{*}{$\mathrm{Q}^{2}(20)$} & $p$-value & 0. & 0.00 & 0.00 & 0.00 & 0.99 & 0.00 & 0.94 & 0.00 & 0.00 & 0.00 & 0.00 \\
\hline & Stat. & 250.8 & 888.27 & 166.38 & 280.2 & 1.18 & 154.9 & 11.06 & 386.1 & 286.8 & 376.23 & 125.35 \\
\hline & $\mathrm{h}$ & 1 & 1 & 1 & 1 & 0 & 1 & 0 & 1 & 1 & 1 & 1 \\
\hline \multirow[t]{2}{*}{$\begin{array}{c}\text { ARCH-L } \\
\text { M (20) }\end{array}$} & $p$-value & 0.000 & 0.00 & 0.00 & 0.00 & 0.99 & 0.00 & 0.98 & 0.00 & 0.00 & 0.00 & 0.00 \\
\hline & Stat. & 155.45 & 408.07 & 119.35 & 182.30 & 1.13 & 120 & 9.42 & 206.8 & 247.3 & 240.01 & 120.82 \\
\hline
\end{tabular}

$\mathrm{Q}(20)$ and $\mathrm{Q}^{2}$ (20) are Ljung-Box or Q statistics for testing the null hypothesis of no autocorrelation in the residuals. The $5 \%$ critical values of $\mathrm{X}^{2}(20)$ distributions is 31.41 . For ADF and PP test, the $1 \%$ critical value is -3.44 .

An interesting result is the correlation between smp and lignite. While a significant positive correlation has been found between electricity prices and coal prices in European Union (ECOFYS, 2016) [54] the price of the domestically produced lignite is not positively correlated with the smp, a result also emphasized in the study of IEA (IEA, 2014) [55]. This will be further examined upon, when 
we present the results of the dynamic conditional correlation. Also, the unconditional correlation between electricity market (smp) and EUA market (eua) was found as expected, positive (0.4376) indicating that there is connection between the price of $\mathrm{CO}_{2}$ quotas and SMP. However the DCC between them is much smaller, as it will be described later on.

By observing Table 4 we conclude that financial, energy and electricity "asset" returns are likely to be non-Gaussian. In all returns the skewness is non-zero, an evidence of a non-symmetric distribution. Furthermore, the kurtosis is significantly in excess $(>3)$ which indicates fat tails of the distribution, containing more probability than a normal distribution. In combination, the log returns of "assets" are leptokurtic. Also, we test the return for normality by applying the Jarque-Bera (JB) test statistic. According to this test the joint null hypothesis is that both skewness and excess kurtosis are zero. As we observe in Table 4, the $p$-value for the JB statistics is zero in all returns, therefore the null hypothesis can safely be rejected, so the returns follow a non-normal distribution.

We have also applied the Augmented-Dickey-Fuller (ADF) and Phillips-Perron (PP) unit root tests. As we observe, both tests give values larger than the critical value for the $1 \%$ level of significance. Therefore, we can reject the null-hypothesis of a unit root for all returns, so they are taken to be stationary.

To detect autocorrelations in the returns we have used the Ljung-Box or Q statistic. From Table 4 also, we see that all returns show signs of statistically significant autocorrelation (gbonds' and ngas' statistics are less than 31.41, but with $p$-values of 0.99 and 0.94 respectively). The strongest autocorrelation is in smp, lignite and load returns (with Q(20) statistics 243.84, 187.97 and 162.24 respectively).

All log returns have a mean zero. GEM wholesale price (smp) returns are most volatile (std. Dev $\simeq 0.16$ ) followed by vstoxx and load returns, while stoxx returns are the less volatile.

All returns show evidence of volatility clustering (ARCH effects) as the visual inspection of the log return (see Figures 9-11) and the ARCH-Lagrangean Multiplier (ARCH-LM) test in Table 4 show, as the test statistic is significantly higher than its critical value for the $5 \%$ significance. The gbonds and ngas returns' test stat is below the critical value, however the corresponding $p$-values are extremely high ( 0.99 and 0.98 respectively), so we cannot refuse the existence of ARCH effects.

Figures 9-11 depict the dynamic evolution of the returns of the time series used. All returns are characterized by the well-known phenomena of volatility clusters. Furthermore, as the figures show, during the aftermath of the Lehman Brothers bankruptcy, September 2008, and during the European Sovereign Debt Crisis, mid 2010, all returns exhibit high level of volatility and the associated clustering. The sample autocorrelation function of the squared returns (not shown here due to space limitation) is slowly decaying, a typical feature for daily 
Athens Stock Exchange, ASE, log ret

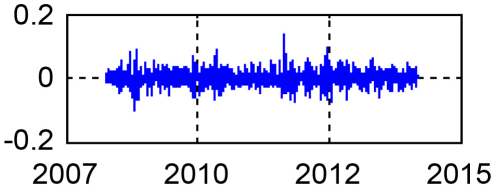

European Stock Vollatility index, log ret

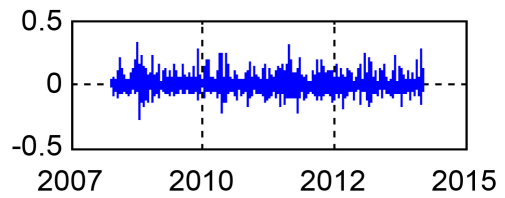

European Stock 50 Index, log ret

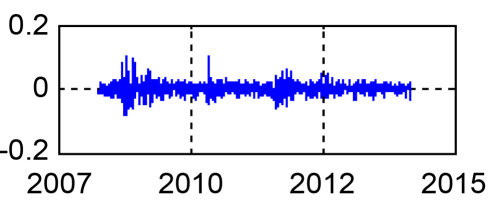

Public Power Coorporation Stock, log ret

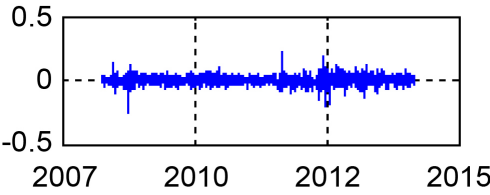

10-year Greek Gen. Goverment bonds yield, log ret

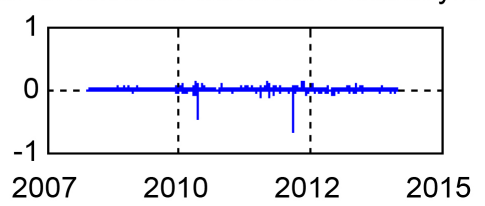

Figure 9. Log-returns of the financial set's time series for the period 10-Sep-2007 to 07-Mar-2014.

European Emissions Allowances, EUA, log returns

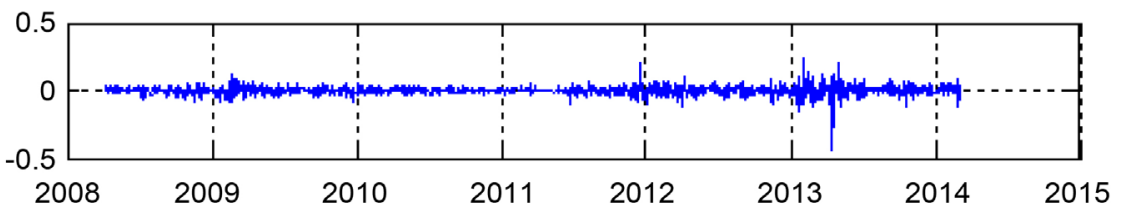

Natural Gas 1 month futures, NBP Hub, log returns

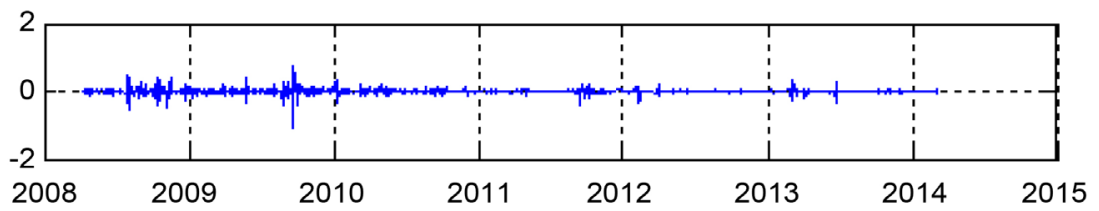

Brent Oil, log returns

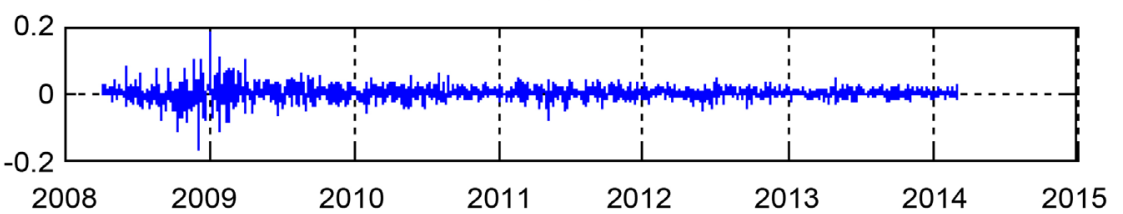

Figure 10. Log-returns of the energy (commodity) data set's time series for the period 10-Sep-2007 to 07-Mar-2014.

returns exhibiting volatility clustering. The ARCH-LM test results, mentioned before, confirm the existence of this stylized fact.

Since all the return series are stationary we proceed by fitting a VAR(1) model for the mean equation (results in Table A1 in appendix). We selected lag order 1 in our model since it is the most parsimonious and no significant difference between the Log Likelihood of higher order models was found. The parameters of 
GEM System Marginal Price, SMP, logreturns

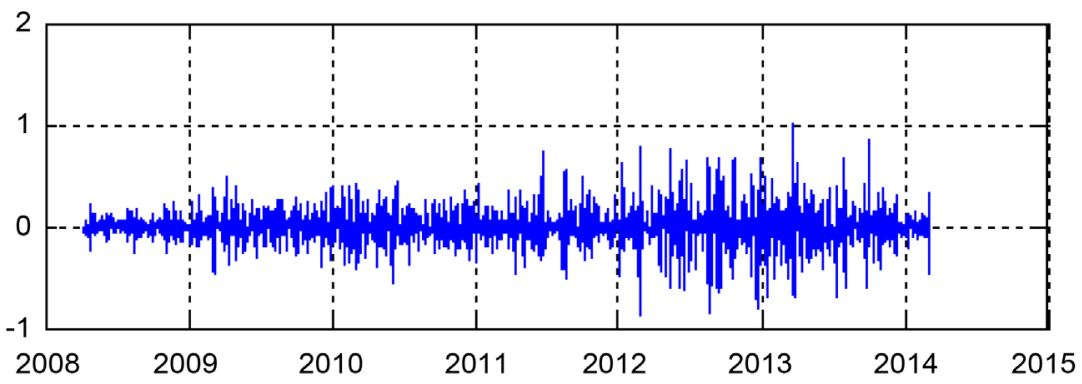

GEM System Wide Load (Demand), logreturns

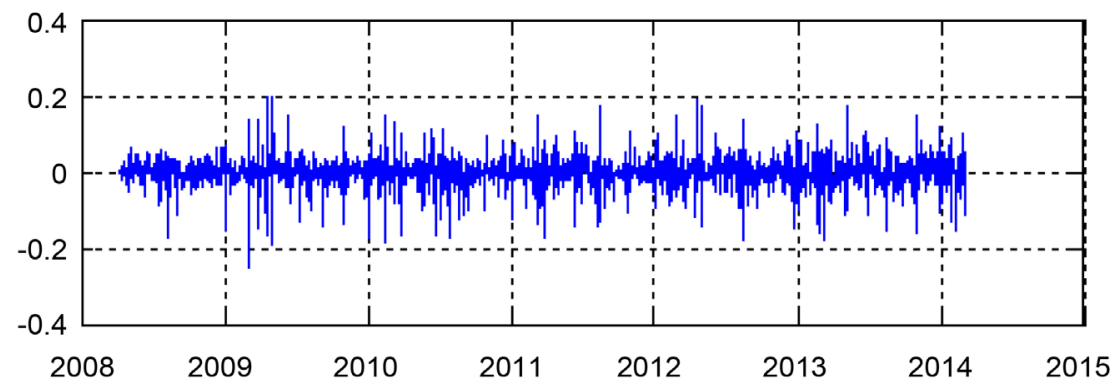

Figure 11. Log-returns of the electricity data set's time series for the period 10-Sep-2007 to $07-$ Mar-2014.

the fitted $\operatorname{GARCH}(1,1)$ model on each individual asset are given in Table 5. After we obtain the residuals from the mean equation we proceed by estimating the DCC between the assets. Table 6 shows the estimation for the DCC-GARCH $(1,1)$ model. The coefficients $\alpha$ and $\beta$ for all pairs of "assets" are positive as required to ensure positive unconditional variances. Also, in all cases, $\alpha+\beta<1$, which supports the existence of dynamic correlations. We have mentioned already that if $\alpha+\beta \sim 1$ then the DCC are highly persistence. Respectively the smallest $\alpha+\beta$, the most anti-persistence the DCC. The pairs with the lowest persistence are lignite_ppc and loadep_eua, with $\alpha+\beta$ equal to 0.33 and 0.76 respectively.

Table 6 shows also, the CCC-model's parameter $\rho$, with positive and negative values. The strongest positive constant conditional correlation is for ase_ppc pair, reflecting a strong linkage between the fluctuations in Athens Stock Exchange (ASE) general Index and the Public Power Corporation's, PPC, Stock price (ppc). Strong and positive (0.47) between ase and stoxx is estimated, while vstoxx is negatively correlated with both ase and stoxx, confirming the theory that equity indexes are positively correlated between each other, and negatively correlated with their corresponding volatility indexes (NIBA, 2016) [56]. In all pairs the value of the parameter $\rho$ is close to the mean value of the DCC over the sample period. In the next section we analyze in depth our findings.

\subsection{Results}

We estimated the dynamic conditional correlations between all of the assets and 
Table 5. Estimated parameters in the $\operatorname{GARCH}(1,1)$ specification.

\begin{tabular}{cccccc}
\hline \multicolumn{5}{c}{ GARCH (1.1) Parameters } & \\
\hline Residuals & $\omega$ & $\boldsymbol{\alpha}_{1}$ & $\beta_{1}$ & $\boldsymbol{\alpha}_{1}+\beta_{1}$ & LL \\
\hline ase_res & 0.0000 & 0.0421 & 0.9264 & 0.9685 & 5621 \\
stoxx_res & 0.0000 & 0.0540 & 0.9351 & 0.9891 & 6480 \\
ppc_res & 0.0001 & 0.0438 & 0.9099 & 0.9536 & 3431 \\
vstoxx_res & 0.0000 & 0.0463 & 0.9436 & 0.9899 & 4684 \\
gbonds_res & 0.0000 & 0.0688 & 0.8964 & 0.9652 & 5074 \\
eua_res & 0.0000 & 0.0900 & 0.9098 & 0.9998 & 5085 \\
ngasUK_res & 0.0000 & 0.0691 & 0.9307 & 0.9998 & 5403 \\
brent_res & 0.0000 & 0.0331 & 0.9652 & 0.9983 & 5989 \\
smp_res & 0.0000 & 0.0305 & 0.8475 & 0.8780 & 5838 \\
loadep_res & 0.0000 & 0.0260 & 0.9729 & 0.9989 & 1209 \\
lignitep_res & 0.0011 & 0.1326 & 0.0000 & 0.1326 & 4131 \\
\hline
\end{tabular}

the most interesting results are presented in Table 6. The conditional correlations between assets from the same market (financial or energy commodity) yield expected results.

Specifically the correlation dynamics between indexes (stoxx and ase) and gbonds firmly confirm the classical macroeconomic approach that in times of rising (falling) stock markets bonds are decreasing (increasing) (Durre A. et al. 2005) [57]. Connoly R, et al. (2002) [58] found that stock and bond returns tend to move together in times of lower stock market uncertainty. However, during periods of high stock market uncertainty (shown e.g. by vstoxx) stock and bond returns tend to exhibit little or even negative relation. We confirm this finding since the conditional correlations between gbonds and the two indexes are strongly negative after 2010, with peak negative values in the midst of the Greek Debt Crisis. Regarding the correlation between ase and stoxx indexes, as shown in Figure 12, it evolved significantly over the period of our sample, with a peak value at the time around the Lehman Brother's collapse and a gradually decrease in the afterwards. Another peak was found in 2010 in the midst of the Greek Sovereign Debt crisis, and in recent years the correlations fluctuate at a lower level. These findings clearly show the effect of the 2 periods of crisis in our sample, since correlations present an upward "jump" in both periods, suggesting that the links between financial assets become stronger in times of stress, confirming the works of others (Kenourgios D., et al. 2011) [59].

Regarding the linkages between the energy commodities (brent, eua and ngasUK) strong positive correlations were found throughout the sample, with higher volatility and peak values in the period of Financial Crisis. Specifically Brent-Eua are highly correlated in periods of financial stress (Koch (2014) [16] also finds a significant rise in their correlation in the same period) and in the 
Table 6. CCC and DCC GARCH(1,1) estimation results.

\begin{tabular}{|c|c|c|c|c|c|c|}
\hline \multirow{4}{*}{\multicolumn{2}{|c|}{ Pair of "Assets" residuals }} & \multicolumn{5}{|c|}{ Estimated Parameters } \\
\hline & & \multirow{3}{*}{$\begin{array}{c}\text { CCC } \\
\text { Model } 1 \\
\rho\end{array}$} & \multicolumn{4}{|c|}{$\operatorname{DCC}(1,1)$} \\
\hline & & & \multicolumn{4}{|c|}{ Model 2 equation (10) } \\
\hline & & & $a$ & $\beta$ & $\alpha+\beta$ & LL \\
\hline ase_res & stoxx_res & 0.4565 & 0.0041 & 0.9954 & 0.9996 & 12394 \\
\hline ase_res & vstoxx_res & -0.3124 & 0.0000 & 0.9998 & 0.9998 & 9180 \\
\hline ase_res & ppc_res & 0.6276 & 0.0066 & 0.9927 & 0.9993 & 10894 \\
\hline ase_res & gbonds_res & -0.2025 & 0.0388 & 0.9552 & 0.9940 & 10806 \\
\hline ase_res & ngasUK_res & 0.0316 & 0.0171 & 0.9179 & 0.9351 & 11031 \\
\hline ase_res & brent_res & 0.1822 & 0.0129 & 0.9797 & 0.9926 & 11667 \\
\hline ase_res & eua_res & 0.0924 & 0.0077 & 0.9815 & 0.9892 & 10726 \\
\hline ase_res & lignite_res & 0.0357 & 0.0068 & 0.9505 & 0.9572 & 11462 \\
\hline gbonds_res & vstoxx_res & 0.1189 & 0.0156 & 0.9813 & 0.9968 & 8543 \\
\hline eua_res & ngasUK_res & 0.1306 & 0.0085 & 0.9664 & 0.9748 & 10511 \\
\hline eua_res & brent_res & 0.2222 & 0.0135 & 0.9759 & 0.9893 & 11147 \\
\hline eua_res & ppc_res & 0.0355 & 0.0118 & 0.9326 & 0.9444 & 9774 \\
\hline eua_res & vstoxx_res & -0.1499 & 0.0159 & 0.9580 & 0.9739 & 8550 \\
\hline eua_res & smp_res & 0.0076 & 0.0387 & 0.3117 & 0.3504 & 6298 \\
\hline eua_res & loadep_res & 0.0340 & 0.0074 & 0.0003 & 0.0076 & 9217 \\
\hline smp_res & ngasUK_res & -0.0029 & 0.0070 & 0.9629 & 0.9699 & 6616 \\
\hline smp_res & loadep_res & 0.2783 & 0.0132 & 0.9344 & 0.9476 & 5434 \\
\hline loadep_res & ase_res & -0.0706 & 0.0297 & 0.2594 & 0.2892 & 9759 \\
\hline smp_res & ase_res & -0.0204 & 0.0070 & 0.9230 & 0.9301 & 6832 \\
\hline lignitep_res & smp_res & -0.0567 & 0.0194 & 0.9286 & 0.9480 & 7055 \\
\hline lignitep_res & eua_res & -0.0119 & 0.0025 & 0.9922 & 0.9947 & 10924 \\
\hline lignitep_res & ngasUK_res & -0.0109 & 0.0000 & 0.9874 & 0.9874 & 11242 \\
\hline lignitep_res & ppc_res & 0.0195 & 0.0000 & 0.0033 & 0.0033 & 10524 \\
\hline gbonds_res & brent_res & -0.0416 & 0.0086 & 0.9880 & 0.9966 & 11074 \\
\hline gbonds_res & ngasUK_res & 0.0433 & 0.0069 & 0.9728 & 0.9797 & 10481 \\
\hline gbonds_res & eua_res & 0.0258 & 0.0428 & 0.0016 & 0.0444 & 10161 \\
\hline stoxx_res & brent_res & 0.3607 & 0.0186 & 0.9728 & 0.9914 & 12691 \\
\hline stoxx_res & eua_res & 0.1723 & 0.0133 & 0.9783 & 0.9916 & 11624 \\
\hline stoxx_res & ngasUK_res & 0.0060 & 0.0194 & 0.9354 & 0.9547 & 11891 \\
\hline smp_res & brent_res & -0.0207 & 0.0033 & 0.3918 & 0.3951 & 7199 \\
\hline ppc_res & brent_res & 0.0791 & 0.0002 & 0.9861 & 0.9862 & 10685 \\
\hline ppc_res & ngasUK_res & 0.0216 & 0.0000 & 0.9017 & 0.9017 & 10089 \\
\hline loadep_res & lignitep_res & -0.0708 & 0.0109 & 0.9637 & 0.9746 & 9977 \\
\hline ppc_res & gbonds_res & -0.1325 & 0.0376 & 0.9553 & 0.9929 & 9798 \\
\hline
\end{tabular}




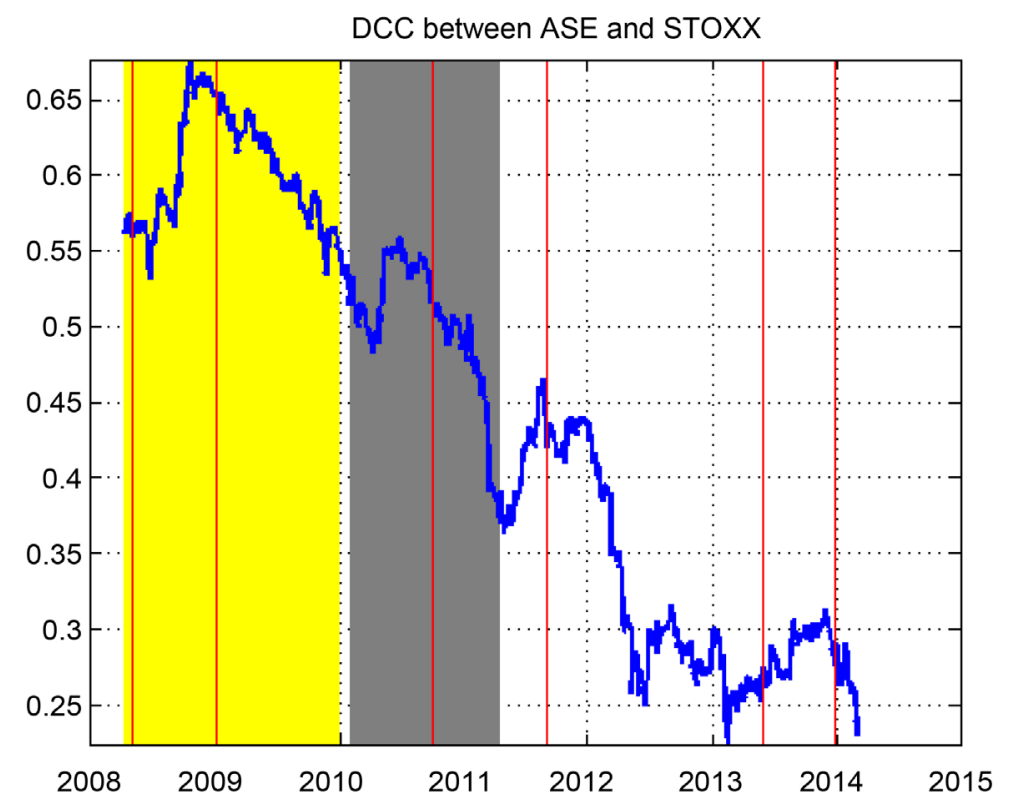

Figure 12. DCC between ase and stoxx residuals.

latter part of our sample converge to their pre-crisis dynamics. In the case of lignite (coal), our findings suggest the uncoupling with the other energy commodities, which was expected since lignite is produced locally and it is not internationally traded.

As our main target is to provide empirical evidence of the coupling or decoupling between the assets of three different markets: the Greek Electricity market, Financial markets, the three most influential commodities markets, Brent Oil, Natural Gas and Carbon allowances (via their corresponding Futures Contracts prices) and for lignite (coal) fuel price, our comments will focus on these pairs and most correlations between assets of the same class will not be further analyzed. Additionally as our sample begins on March 2008 the well documented effect of the 2007 subprime financial crisis in the USA, will be omitted by our analysis, and our work will be focused on the 2010 Greek debt crisis and thereafter. We wish to analyze the coupling and decoupling periods between the markets under consideration, as well as demonstrate the Greek debt crisis effects in the Greek electricity market versus the other two markets, as well as the convergence of the markets' dynamics to pre-crisis levels, thereafter. In general we expect correlations between assets from different sectors to be lower than the ones of assets from the same sector, as can be shown in the work of Ensor, et al. (2014) [60].

\subsection{DCC between Financial Market and Energy Commodities}

The financial crisis, which begun in 2007, had a significant effect on the correlations between financial markets and energy commodities. The stock market collapse significantly decreased the correlations between stock markets and energy markets returns, as documented Creti (2013) [61], possibly due to the 
"flight-to-quality" effect, but only on the short run, followed by a sharp increase in correlations which remained for the following years, resulting in high correlation in the volatility and the "financialization" of the energy markets. Figure 13 compares the results correlations between ASE and stoxx with the 3 most liquid energy commodities of Europe.

Our sample begins in April of 2008, in the midst of the Financial crisis period and all correlations between ase and energy commodities present a peak negative value. Specifically correlation between Brent oil, which is the energy commodity most related with the stock market due to the "speculation effect" (increasing crude prices in times of rising stock markets) and the Greek stock market has a significant evolution in the period of our study, with a positive peak 0.45 in the mid of the Greek debt crisis. Comparing the correlations between ase and stoxx with brent oil, as seen in Figure 13, we observe a similar evolution in time, with the stoxx-brent being significantly higher and more volatile, during the years of the Greek debt crisis and afterwards.

Similarly correlations between EUA returns and the indexes both peaked around the Lehman Brothers collapse, when it became apparent that the financial crisis, which up until then was contained within the financial sector, would affect the real economy and slow down economic growth, thus confirming the "contagion" effect. In the following years correlations, especially with stoxx remained mostly positive and highly volatile. EUA as a commodity reflects the economic growth as expressed by industrial production, and the decreased production in Greece, with consideration of the structure of the Greek electricity market (lignite, a $\mathrm{CO}_{2}$-intense fuel, is a "cheap" domestically produced resource in the GEM), results in the decoupling of the two markets.

Finally correlation between Natural gas and the Greek stock market increased in the beginning of our sample and remain fairly stable in the whole period, with a slightly increased volatility during the period of Greek Debt Crisis. This behavior is consistent with the evolution of the stoxx-gas conditional correlation, suggesting that natural gas has the weakest link to equity markets. Regarding the Greek market, a more concrete and robust analysis should be undertaken, using Natural Gas prices provided from the Greek Natural Gas System Operator (DESFA), in order to check any dependencies with not publicly traded (exchange) markets, but on a bilateral trading rationale between Greece and other countries, e.g. Russia, Algeria.

Turning to the relations between 10-year Greek bonds and energy commodities, our results in Figure 14 depict that the Greek debt crisis of 2010 had a significant effect on the evolution of conditional correlation, with peak values and increased volatilities, which persisted in the following years. In particular correlation between brent and gbonds intensified from around 0 to around -0.26 , while correlation between gbonds and natural gas peaked to a positive 0.18. These peaks correspond with significant highs for ase-brent and lows for ase-ngas, confirming the notion that times with stronger (weaker) stock-commodities 
DCC between financial markets and energy commodities
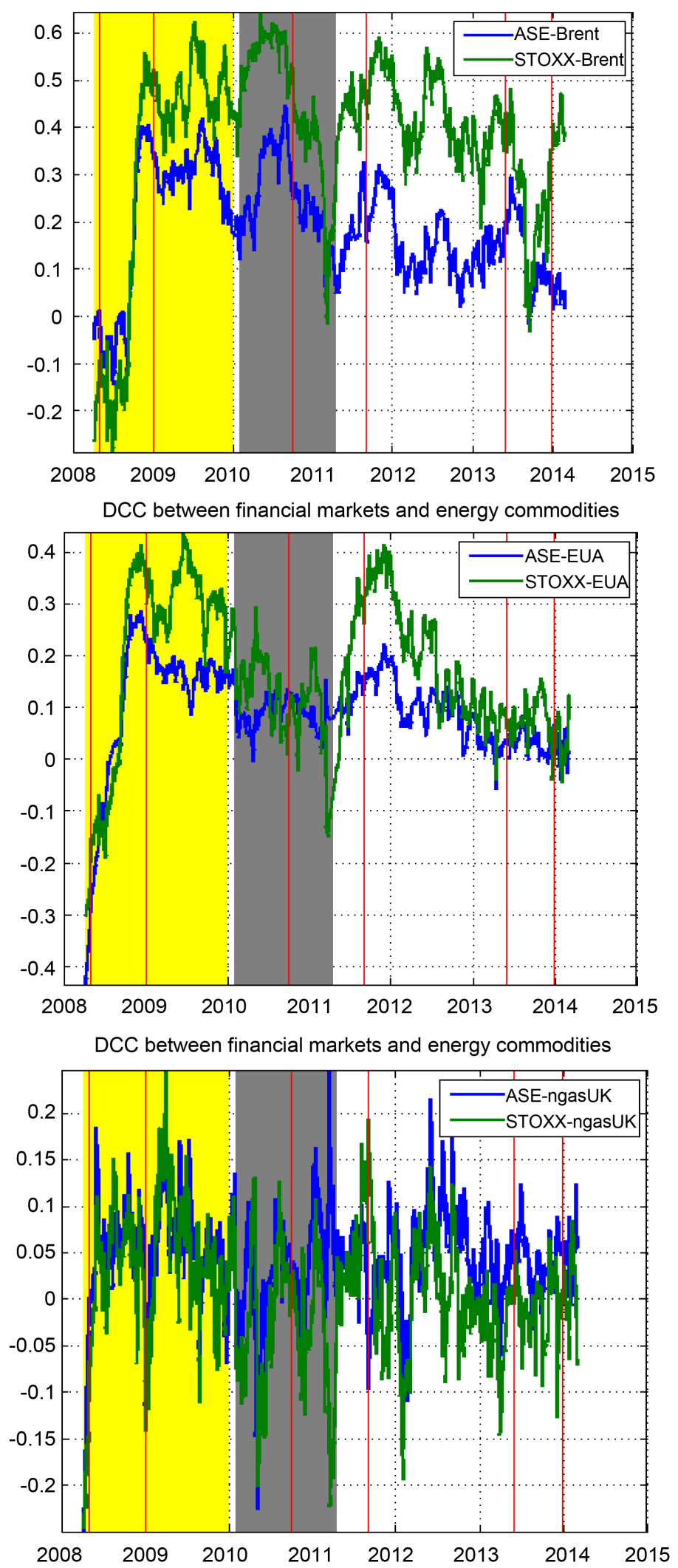

Figure 13. DCC of ase and stoxx with the 3 energy commodities (brent, eua and natural gas). 


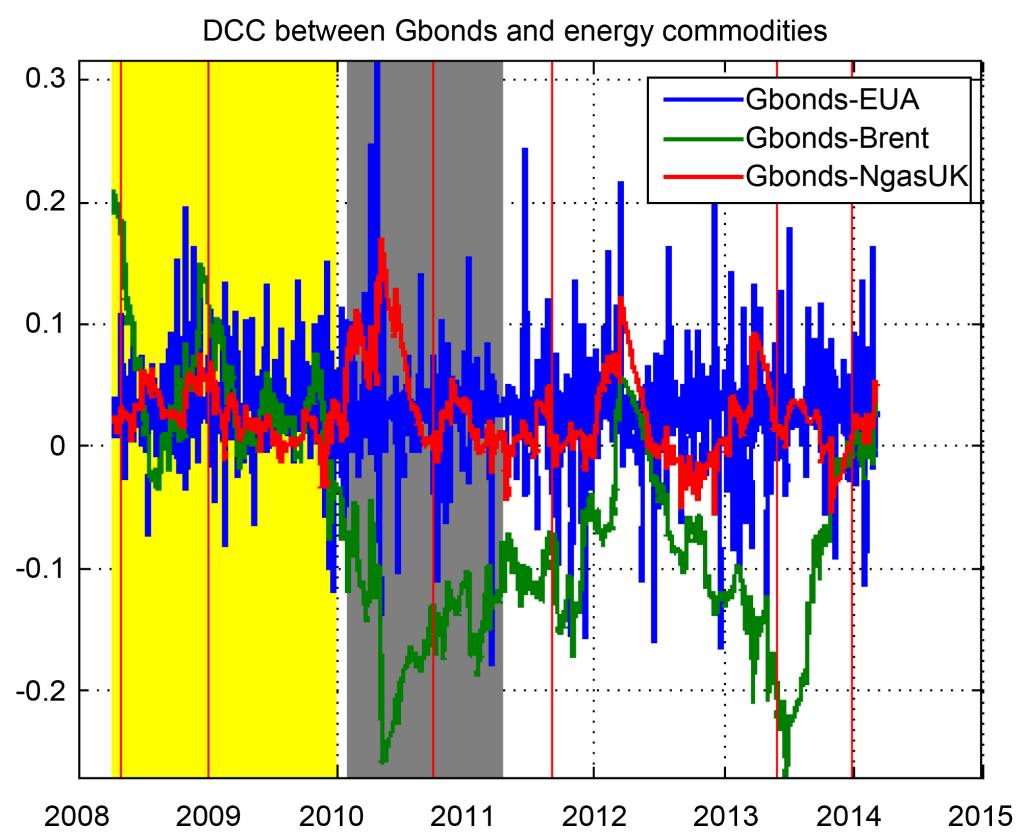

Figure 14. DCC between gbonds and energy commodities.

co-movements correspond to times with weaker (stronger) bonds-commodities co-movements. Finally eua-gbonds present a highly anti-persistent conditional volatility which oscillates close to zero, which suggests no significant link between the assets.

Examining the linkages between PPC, the main player of GEM, and energy commodities, the conditional correlations are presented in Figure 15. Natural gas presents non significant result, as expected, since PPC's energy production portfolio consists of mainly lignite, hydro and to a lesser degree gas fired production units. Brent oil and ppc correlations converge to an almost constant and very low correlation close to 0.1 and present no evolution during the period of our study. EUA has a persistent and volatile correlation with ppc, with maximum value of 0.24 and minimum of -0.13 , with more negatives values exhibited during the years following the Greek debt crisis. The correlation between ppc and lignite present substantial evidence of the uncoupled market behavior between the financial market in Greece and the primary materials (fuels) used for energy generation in Greece. This behavior is consistent with the fact that Lignite is in abundance in Greece, and is used in a great portion by PPC for power production, i.e. PPC is allocating a great portion of its internal production strategy on lignite for power generation. As seen in Figure 15 PPC is highly correlated with ase, as PPC is a major representative of the Greek stock market (Blue chip).

Overall our results depict a strong linkage between financial and energy commodity markets in periods of financial turmoil, with Brent and EUA being the most "finacialized commodities", with correlations that remained highly volatile throughout the Greek debt crisis and move towards decoupling in the years after. 


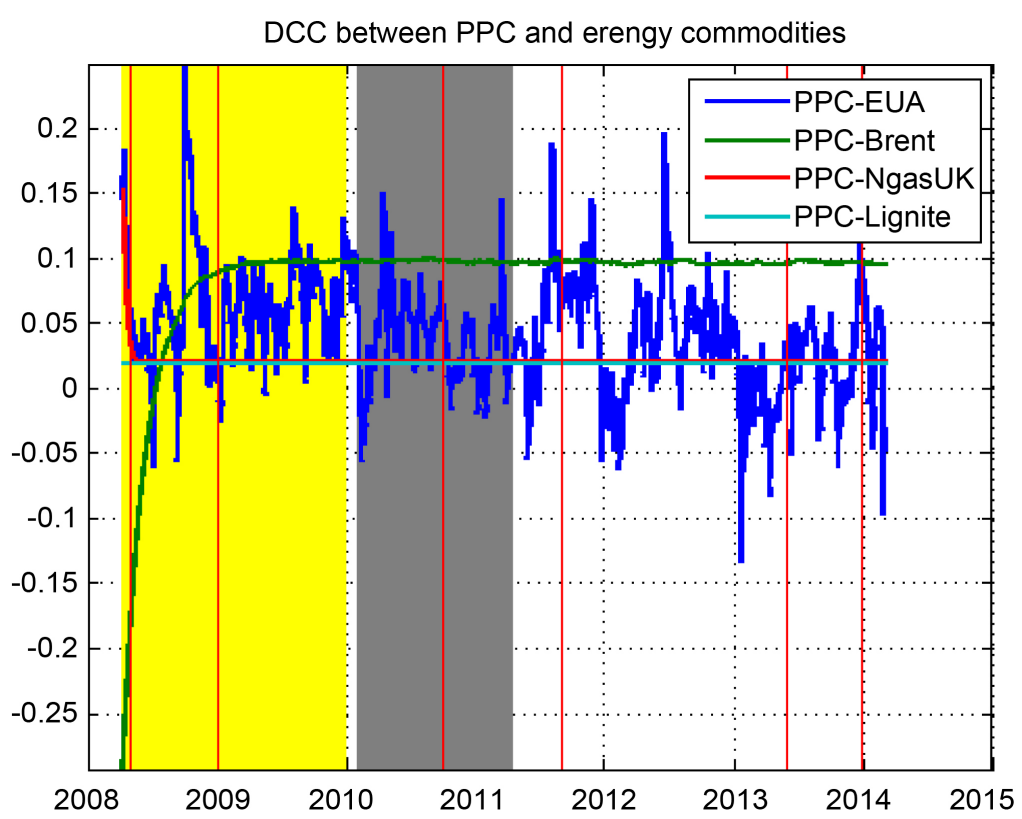

(a)

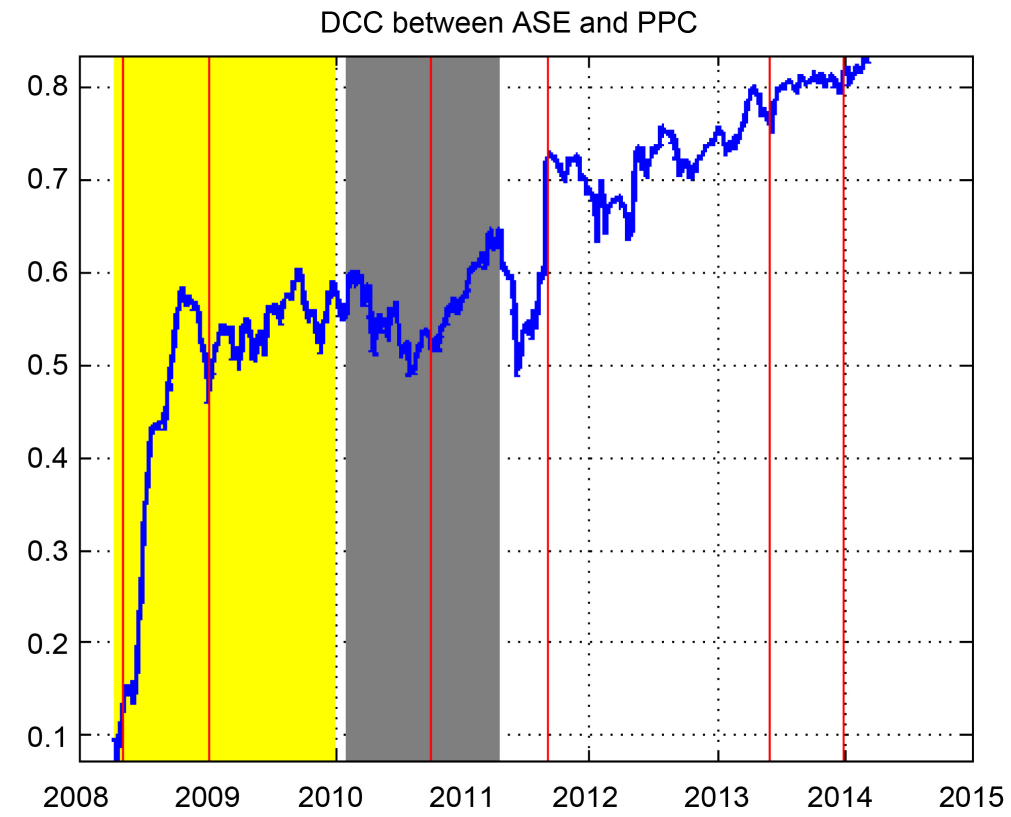

(b)

Figure 15. DCC between pcc and energy commodities (a) and ppc and ase respectively (b).

\subsection{DCC between Greek Electricity Market and Energy Commodities}

Our findings suggest that GEM's spot electricity price (SMP) presents significant correlation with the load forecast, which was expected since supply and demand must be in a constant equilibrium in order for the network to operate properly.

The Greek electricity market operates under the merit order principle, meaning that the order of the existing power plants to be dispatched follows the as- 
cending order of the respective fuel variable costs, with renewable energy sources being dispatched first, followed by lignite power plants. Natural gas has the higher variable cost and oil is used only for extreme peaks in demand. The last power plant to enter production in order to cover the demand, also sets the uniform market price (IEA, 2014) [55].

Correlations between smp and brent oil are insignificant since it's rarely used, thus almost never sets the price. Regarding natural gas, correlations are mostly positive with smp and tend to increase in the latter years. Again, a more concrete and robust analysis should be undertaken, using Natural Gas prices DESFA, in order to truly capture the dynamics with the electricity prices. Correlations with EUA are highly anti-persistent, as suggested by the results in Table 6, but no significant link is evidenced, although lignite comprise a great portion of the incumbent's (PPC) fuels portfolio allocation for power production. This can be attributed to the flexibility to shift between alternative production units (mainly hydroelectric) and the non competitive nature of the lignite "market" (actually there is no market), thus no need to hedge with EUA is present. These results are shown in Figure 16.

Finally turning to the pair smp-lignite, the conditional correlation is volatile and mostly negative. Lignite is in abundance in Greece and while its price increases over time, it remains lower most of the time than the fuel variable cost of a gas power plant, meaning that when the price is set by lignite fired plants it's decreasing (IEA, 2014) [55], thus the mostly negative correlation.

\subsection{DCC between Greek Electricity Market and Financial Markets}

Turning to the correlations between electricity and financial markets, we present in Figure 17 substantial evidence that the two markets are uncoupled. The electricity spot market is heavily driven by a few crucial variables already mentioned above, and is fundamentally based on non-financial factors, such as non-storability of electricity, inelasticity of supply etc. These findings are similar to the works of others regarding dynamic correlations between financial and electricity markets (Creti, et al. (2013) [61]). Load is experiencing a cyclical behavior, which is consistent with the consumers' needs for electricity during the several seasons (winter vs summer etc), while the financial market has not such dependency on "seasonalities".

\section{Conclusions}

In this paper we have investigated the pairwise dynamics of return conditional correlation between assets "belonging" to three markets, namely electricity, energy commodity and financial. By using Dynamic Condition Correlation model, a model with proven computational advantages, also chosen due to the data stylized facts (e.g. fat tails, volatility clustering etc. of the assets in each market, suggesting a GARCH-type estimation framework), we have examined the co-movement of co-volatility between pairs of assets of these 3 markets. 


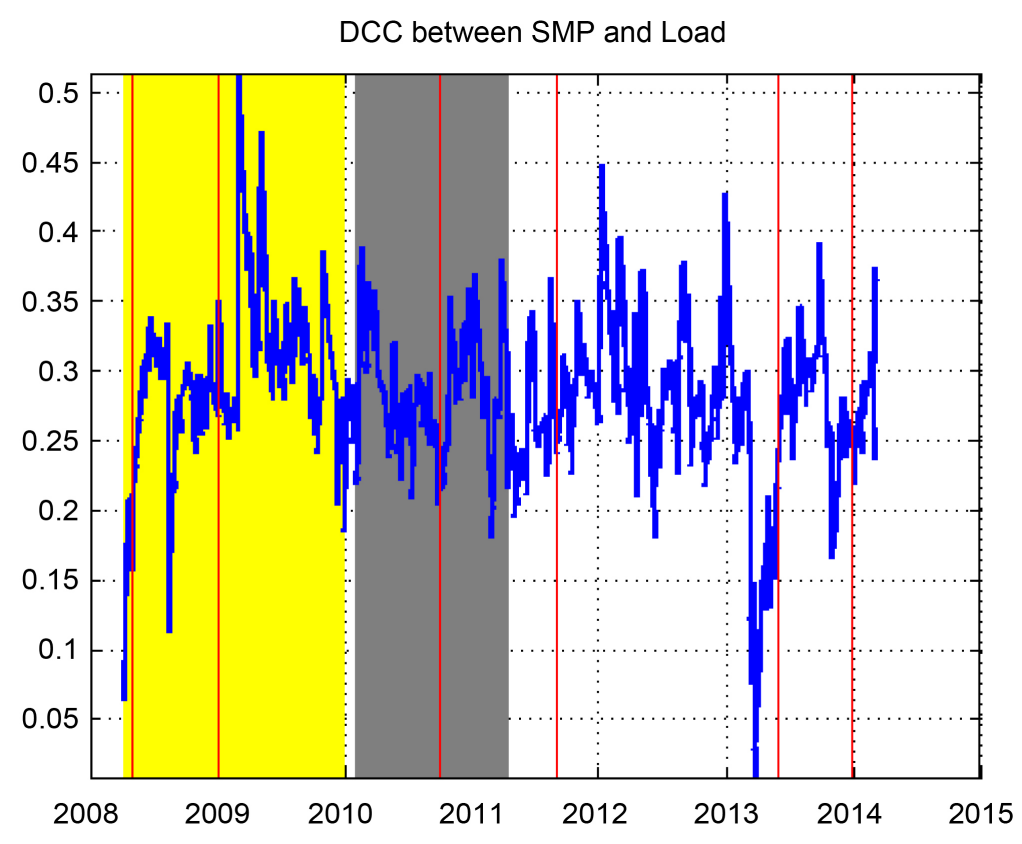

DCC between smp and erengy commodities

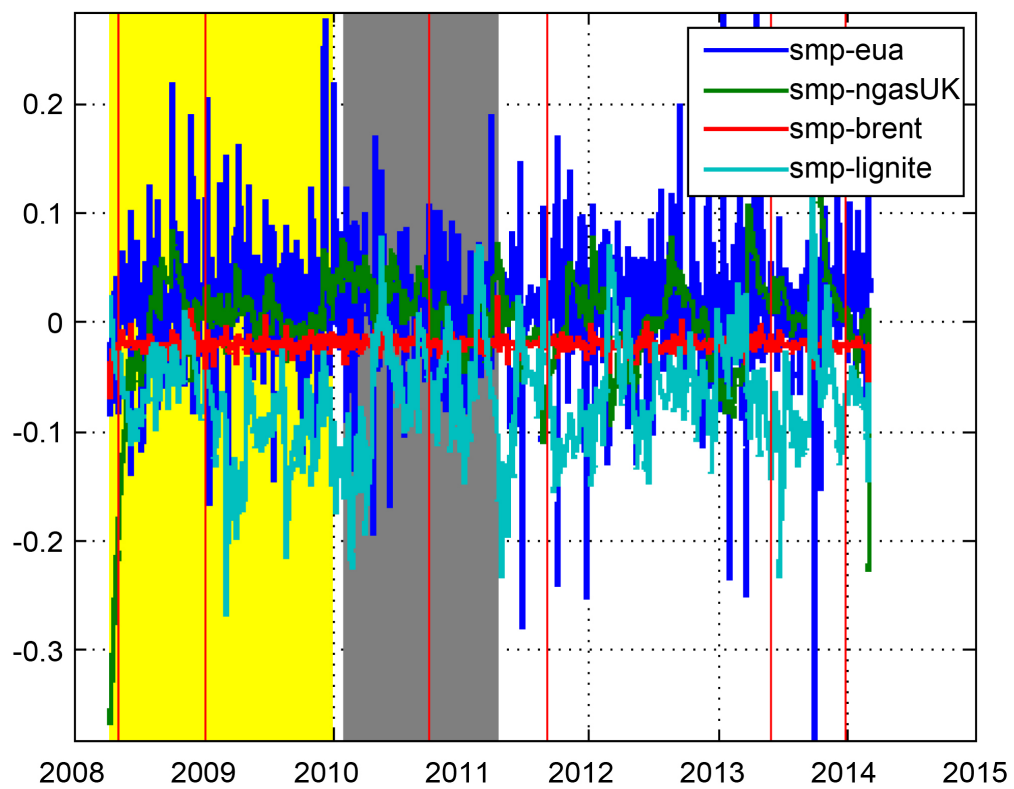

Figure 16. DCC between smp and load (up) and between smp and energy (down) respectively.

Emphasis was given in the effects of the 2008 financial as well as the 2010 Greek Sovereign debt crisis on the pairwise DCC of the markets.

We present evidence of significant co-movements between financial market and energy commodities, namely Brent oil and carbon allowances, in periods of financial turmoil, with strong positive and highly volatile correlations. These findings confirm the volatility spillover between these two markets and prove the "financialization" of these energy commodities. Overall the correlations between financial and energy commodities were the most significant between the 


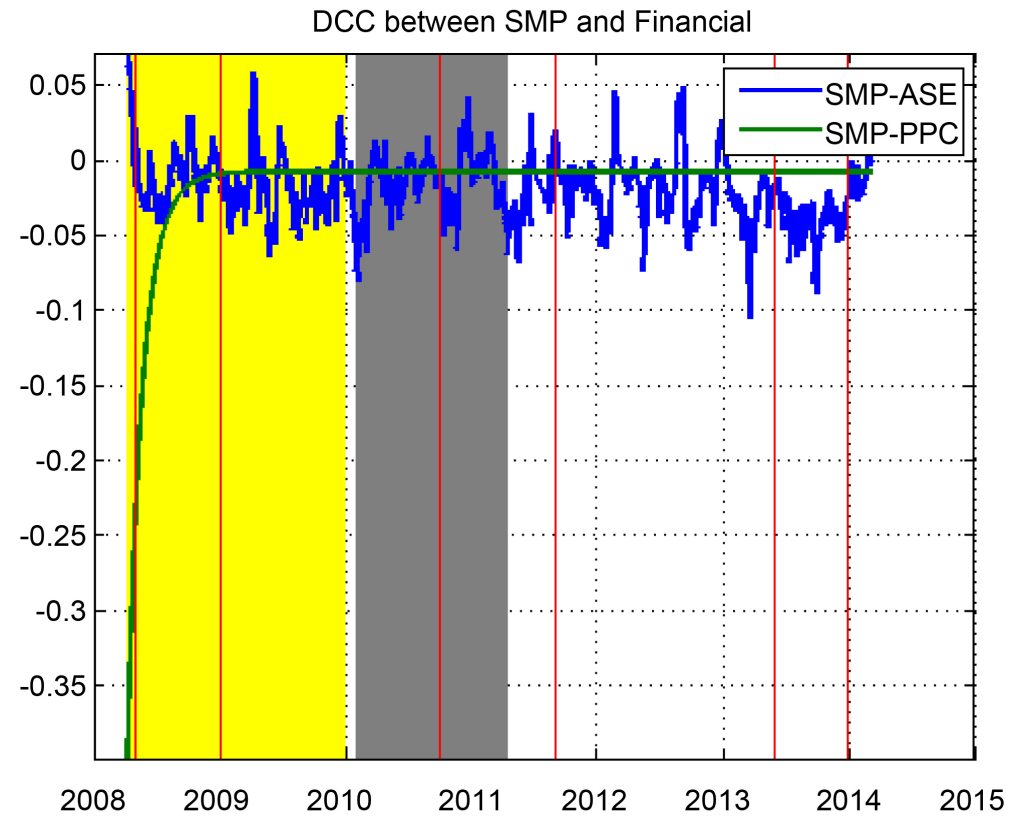

Figure 17. DCC between smp and financial commodities.

different classes of assets.

Regarding the linkages of the Greek Electricity Market, lower conditional correlations were found with the financial and energy market respectively and the periods of financial crisis of 2008 and the Greek Sovereign Debt crisis do not seem to have had a significant effect in the evolution of the dynamic linkages between GEM and other two markets. Finally mostly negative correlations were found between the indigenous lignite price and the System Marginal Price, suggesting that while lignite's price rises over the years, coal-fired plants are decreasing the price when they set the price via the merit order principle.

We conclude that there is limited liquidity in the GEM which causes spot market's dynamics to be dependent not only on load forecast but also on the strategic position of the dominant player of this market. Since the Greek Electricity Market is in a transitional phase with the upcoming market coupling with Italy as well as with the upcoming introduction of new markets (intra-day market, balancing market) we expect higher linkage with the other two markets in the next years.

\section{References}

[1] Bermejo-Aparicio, R., Moreno, M. and Villaplana, P. (2008) European Natural Gas Spot Markets: Volatility Transmission and Jumps Modeling. Retrieved on the 02.02.2012 from

https://editorialexpress.com/cgi-bin/conference/download.cgi?db_name=forofinanz as2008\&paper_id=127

[2] Engle, R.F., Kroner, K.F. (1995) Multivariate Simultaneous Generalized ARCH. Econometric Theory, 11, 122-150. https://doi.org/10.1017/S0266466600009063

[3] Regnard, N. and Zakoian, J.-M. (2011) A Conditionally Heteroskedastic Model with 
Time-Varying Coefficients for Daily Gas Spot Prices. Energy Economics, 33, 1240-1251. https://doi.org/10.1016/j.eneco.2011.02.004

[4] Asche, F., Osmundsen, P., Sikveland, M. and Tveteras, R. (2009) Volatility and risk sharing in European gas markets. Retrieved on the 05.02.2012 from

http://www.usaee.org/usaee2009/submissions/OnlineProceedings/Volatility\%20and \%20risk\%20sharing\%20in\%20European\%20gas\%20markets\%20IAAE\%20Procedin gs.pdf

[5] Chevallier, J. (2012) Time-Varying Correlations in Oil, Gas and $\mathrm{CO}_{2}$ Prices: An Application Using BEKK. CCC and DCC-MGARCH models. Applied Economics, 44, 4257-4274. https://doi.org/10.1080/00036846.2011.589809

[6] Mansanet-Bataller, M. and Soriano, P. (2009) Volatility Transmission in the $\mathrm{CO}_{2}$. Energy Markets. EEM 2009, 6th International Conference on the European Energy Market. https://doi.org/10.1109/EEM.2009.5207131

[7] Mansanet-Bataller, M. (2011) $\mathrm{CO}_{2}$ Prices and Portfolio Management during Phase II of the EU ETS. Climate Economics Chair Publications Working Paper Series.

[8] Alberola, E., Chevallier, J. and Cheze, B. (2008) Price Drivers and Structural Break in European Carbon Prices 2005-2007. Energy Policy, 36, 787-797. https://doi.org/10.1016/j.enpol.2007.10.029

[9] Hintermann, B. (2010) Allowance Price Drivers in the first Phase of the EU ETS. Journal of Environmental Economics and Management, 59, 43-56. https://doi.org/10.1016/j.jeem.2009.07.002

[10] Rickels, W., Gorlich, D. and Oberst, G. (2010) Explaining European Emission Allowance Price Dynamics: Evidence from Phase II. Kiel Working Paper No. 1650.

[11] Chevallier, J. (2011a) Detecting Instability in the Volatility of Carbon Prices. Energy Economics, 33, 99-110. https://doi.org/10.1016/j.eneco.2010.09.006

[12] Bredin, D. and Muckley, C. (2011) An Emerging Equilibrium in the EU Emissions Trading Scheme. Energy Economics, 33, 353-362. https://doi.org/10.1016/j.eneco.2010.06.009

[13] Bunn, D. and Fezzi, C. (2007) Interaction of European Carbon Trading and Energy Prices. Fondazione Eni Encico Mattei Working Paper 123. https://doi.org/10.2139/ssrn.993791

[14] Nazifi, F. and Milunovich, G. (2010) Measuring the Impact of Carbon Allowance: Trading on Energy Prices. Energy and Environment, 21, 367-383. https://doi.org/10.1260/0958-305X.21.5.367

[15] Keppler, J.H. and Mansanet-Bataller, M. (2010) Causalities between $\mathrm{CO}_{2}$, Electricity and Other Energy Variables during Phase I and Phase II of the EU ETS. Energy Policy 38, 3329-3341. https://doi.org/10.1016/j.enpol.2010.02.004

[16] Koch, N. (2014) Dynamic Linkages among Carbon, Energy and Financial Markets: A Smooth Transition Approach. Applied Economics, 46, 715-729. https://doi.org/10.1080/00036846.2013.854301

[17] Fama, E.F. and French, K.R. (1989) Commodity Futures Prices: Some Evidence on Forecast Power, Premiums, and the Theory of Storage. The Journal of Business, 25, 23-49.

[18] Sadorsky, P. (2002) Time-Varying Risk Premiums in Petroleum Futures Prices. Energy Economics, 24, 539-556. https://doi.org/10.1016/S0140-9883(02)00062-2

[19] Chevallier, J. (2009) Carbon Futures and Macroeconomic Risk Factors: A View from the EU ETS. Energy Economics, 31, 614-25.

https://doi.org/10.1016/j.eneco.2009.02.008 
[20] Koening, P. (2011) Modelling Correlation in Carbon and Energy Markets. EPRG Working Paper 1107, Electricity Policy Research Group, Cambridge.

[21] Springer, U. (2003) The Market for Tradable GHG Permits under the Kyoto Protocol: A Survey of Model Studies. Energy Economics, 25, 527-551. https://doi.org/10.1016/S0140-9883(02)00103-2

[22] Rubin, J.D. (1996) A Model of Intertemporal Emission Trading, Banking, and Borrowing. Journal of Environmental Economics and Management, 31, 269-286. https://doi.org/10.1006/jeem.1996.0044

[23] Tietenberg, T.H. (2006) Emissions Trading: Principles and Practices. Resources for the Future, Washington.

[24] Delarue, E. and D'haeselear, W. (2008) Greenhouse Gas Emission Reduction-Potential by Means of Fuel Switching in Electricity Generation: Addressing the Potentials. Energy Conversion and Management, 49, 843-853. https://doi.org/10.1016/j.enconman.2007.06.026

[25] Trotignon, R. and Delbosc, A. (2008) Allowance Trading Patterns during the EU ETS Trial Period: What Does the CITL Reveal? CDC Climate Report Issue No. 13.

[26] Ellerman, D. and Buchner, B. (2008) Over-Allocation or Abatement? A Preliminary Analysis of the EU ETS Based on the 2005-06 Emissions Data. Environmental and Resource Economics, 41, 267-287. https://doi.org/10.1007/s10640-008-9191-2

[27] Alberola, E., Chevallier, J. and Cheze, B. (2009) Emissions Compliances and Carbon Prices under the EU ETS: A Country Specific Analysis of Industrial Sectors. Journal of Policy Modeling, 31, 446-462. https://doi.org/10.1016/j.jpolmod.2008.12.004

[28] Bonacina, M. and Cozialpi, S. (2009) Carbon Allowances as Inputs or Financial Assets: Lesson Learned from the Pilot Phase of the EU-ETS. IEEE Working Paper No. 19 (2009). https://doi.org/10.2139/ssrn.1392177

[29] Bessembinder, H and Chan, K. (1992) Time-Varying Risk Premia and Forecastable Returns in Futures Markets. Journal of Financial Economics, 32, 169-193. https://doi.org/10.1016/0304-405X(92)90017-R

[30] Daskalakis, G, Psychoyios, D. and Markellos, R.N. (2009) Modeling $\mathrm{CO}_{2}$ Emission Allowances Prices and Derivatives: Evidence from the European Trading Scheme. Journal of Banking and Finance, 33, 1230-1241. https://doi.org/10.1016/j.jbankfin.2009.01.001

[31] Gronwald, M., Ketterer, J. and Truck, S. (2011) The Relationship between Carbon, Commodity and Financial Markets-A Copula Analysis. Economic Record, 87, 105-124. https://doi.org/10.1111/j.1475-4932.2011.00748.x

[32] Kanamura, T. (2010) Financial Turmoil in Carbon Markets. SSRN eLibrary. https://doi.org/10.2139/ssrn.1652735

[33] Borak, S., Hardle, W., Truck, S. and Weron, R. (2006) Convenience Yields for $\mathrm{CO}_{2}$ Emission Allowance Futures Contracts. SFB 649 Discussion Paper No. 2006-076. https://doi.org/10.2139/ssrn.2894390

[34] Benz, E. and Truck, S. (2006) $\mathrm{CO}_{2}$ Emission Allowances Trading in Europe: Specifying a New Class of Assets. Problems and Perspectives in Management, 4, 30-40.

[35] Veith, S., Wegner, J.R. and Zimmermann, J. (2009) Capital Market Response to Emission Rights Returns: Evidence from the European Paper Sector. Energy Economics, 31, 605-618. https://doi.org/10.1016/j.eneco.2009.01.004

[36] Chevallier, J. (2009b) Energy Risk Management with Carbon Assets. International Journal of Global Energy Issues, 32, 328-349.

https://doi.org/10.1504/IJGEI.2009.032335 
[37] Mizrach, B. and Otsubo, Y. (2011) The Market Microstructure of the European Climate Exchange. SSRN Working Paper No. 1621640, Rutgers University, New Brunswick, NJ.

[38] RAE (2009, 2010, 2011) National Reports to the European Commission, Regulatory Authority for Energy, RAE's Website: http://www.rae.gr/

[39] Kalantzis F. and Sakelaris, K. (2012) Investigating the Impact of the Greek Electricity Market Reforms on its Day-Ahead Market Prices, MRPA Paper No. 37794, April 2012.

[40] Engle, R.F. (1982) Autoregressive Conditional Heteroskedasticity with Estimates of the Variance of U.K. Inflation. Econometrica, 50, 1-50. https://doi.org/10.2307/1912773

[41] Bollerslev, T. (1986) Generalized Autoregressive Conditional Heteroskedasticity. Journal of Econometrics, 31, 4-15. https://doi.org/10.1016/0304-4076(86)90063-1

[42] Benz, E., Truck, S. (2009) Modeling the Price Dynamics of $\mathrm{CO}_{2}$ Emission Allowances. Energy Economics, 34, 4-15. https://doi.org/10.1016/j.eneco.2008.07.003

[43] Taylor, S.J. (1986) Modelling Financial Time Series. John Wiley and Sons Ltd, Hoboken, New Jersey.

[44] Zakoian. J.M. (1994) Threshold Heteroskedastic Models. Journal of Economic Dynamics and Control, 18, 931-955. https://doi.org/10.1016/0165-1889(94)90039-6

[45] Glosten, L.R., Jagannathan, R and Runkle, D. (1993) Relationship between the Expected Value and the Volatility of the Nominal Excess Return on Stocks. Journal of Finance, 48, 1779-1802. https://doi.org/10.1111/j.1540-6261.1993.tb05128.x

[46] Bollerslev, T. (1990) Modelling the Coherence in Short-Run Nominal Exchange Rates; A multivariate Generalized ARCH Model. Review of Economics and Statistics, 72, 498-505. https://doi.org/10.2307/2109358

[47] Silvennoinen. A. and Tersvirta. T. (2007) Multivariate Garch Models. URL https://link.springer.com/chapter/10.1007/978-3-540-71297-8_9

[48] Engle, R.F. (2002) Dynamic Conditional Correlation. A Simple Class of Multivariate Garch Models. Journal of Business \& Economic Statistics, 20, 339-350. https://doi.org/10.1198/073500102288618487

[49] Engle, R.F. and Sheppard, K. (2001) Theoretical and Empirical Properties of Dynamic Conditional Correlation Multivariate GARCH. Mimeo. UCSD. https://doi.org/10.3386/w8554

[50] Aielli, G. (2009) Dynamic Conditional Correlations: On Properties and Estimation. Technical Report. Department of Statistics. University of Florence.

[51] Cappielo, L., Engle, R.F., Sheppard, K. (2006) Asymmetric Dynamics in the Correlations of Global Equity and Bond Returns. Journal of Financial Econometrics, 4, 537-572. https://doi.org/10.1093/jjfinec/nbl005

[52] Hafner, C. and Frances, P. (2009) A Generalized Dynamic Conditional Correlation Model: Simulation and Application to Many Assets. Econometric Reviews, 28, 612-631. https://doi.org/10.1080/07474930903038834

[53] Vargas. G.A. (2008) What Drives the Dynamic Conditional Correlation of Foreign Exchange and Equity Returns? SSRN eLibrary. URL http://ssrn.com/paper=1093286

[54] ECOFYS (2016) Prices and Costs of EU Energy, Annex 2 Econometrics.

[55] IEA (2014) The Impact of Global Coal Supply on Worldwide Electricity Prices, International Energy Agency. Insights Series 2014.

[56] National Introducing Brockers Association, NIBA (2016) Utilizing a European Vo- 
latility Index for Pan-European Volatility, Resource Articles.

https://www.theniba.com/category/resource-articles/

[57] Durre, A. and Giot, P. (2005) An International Analysis of Earnings, Stock Prices and Bond Yields. Working Paper Series No. 515/ August 2005, ECB. https://doi.org/10.2139/ssrn.1690509

[58] Connoly, R., Stivers, C. and Sun, L. (2005) Stock Market Uncertainty And Stock-Bond Relation. Journal of Financial and Quantitative Analysis, 40, 161-194. https://doi.org/10.1017/S0022109000001782

[59] Kenourgios, D., Samitas, A. and Palaliolis, N. (2011) Financial Crises and Stock Market Contagion in a Multivariate Time-Varying Asymmetric Framework. Journal of International Markets, Institutions and Money, 21, 92-106. https://doi.org/10.1016/j.intfin.2010.08.005

[60] Ensor, B.K. and Koev, G.M. (2014) Computational Finance: Correlation, Volatility and Markets. WIREs Compute Stat 2014, 6, 326-340. https://doi.org/10.1002/wics.1323

[61] Creti, A., Joets, M. and Mignon, V. (2013) On the Links between Stock and Commodity Market's Volatility. Energy Economics, 37, 16-18.

https://doi.org/10.1016/j.eneco.2013.01.005 


\section{Appendix}

Table A1. (a) Estimated constants of the VAR(1) model. (b) Estimated Autoregression coefficients of the VAR(1) model.

(a)

\begin{tabular}{ccc}
\hline & constant \\
\hline ase & -0.0005 \\
stoxx & -0.0001 \\
vstoxx & -0.0002 \\
gbonds & -0.0002 \\
eua & 0.0001 \\
ngasUK & -0.0005 \\
brent & 0.0000 \\
smp & 0.0000 \\
loadep & 0.0004 \\
lignitep & 0.0000 \\
\hline
\end{tabular}

(b)

\begin{tabular}{|c|c|c|c|c|c|c|c|c|c|c|c|}
\hline Coefficients & "ase" & "stoxx" & "vstoxx" & "ppc" & "gbonds" & "eua" & "ngUK" & "brent" & "smp" & "load" & "lignite" \\
\hline “ase(-1)” & -0.0295 & 0.1717 & 0.0101 & 0.0301 & -0.0145 & -0.0107 & -0.0283 & 0.0042 & 0.0101 & -0.0041 & 0.0049 \\
\hline "stoxx(-1)" & 0.0208 & 0.0222 & 0.0089 & 0.0077 & -0.0038 & 0.0010 & -0.0273 & -0.0009 & -0.0022 & -0.0007 & -0.0112 \\
\hline “vstoxx(-1)" & -0.2317 & -0.2081 & -0.0738 & 0.0066 & 0.0336 & -0.0103 & 0.1524 & -0.0568 & 0.0392 & -0.0038 & 0.0383 \\
\hline "ppc(-1)" & 0.0005 & 0.1182 & -0.0049 & 0.0651 & 0.0085 & -0.0079 & -0.0320 & -0.0485 & -0.0127 & -0.0109 & 0.0202 \\
\hline "gbonds(-1)" & -0.0511 & -0.1269 & -0.0146 & -0.0193 & 0.0763 & -0.0111 & 0.0319 & 0.0468 & -0.0178 & 0.0050 & 0.0075 \\
\hline “eua(-1)” & 0.0602 & -0.0016 & 0.0248 & -0.0106 & 0.0091 & 0.0552 & -0.0178 & -0.0769 & -0.0256 & 0.0057 & -0.0317 \\
\hline "ngUK(-1)" & -0.0447 & 0.0016 & -0.0140 & -0.0042 & -0.0186 & 0.0174 & 0.0023 & -0.0497 & 0.0246 & 0.0013 & -0.0014 \\
\hline "brent(-1)" & -0.0127 & 0.0411 & 0.0151 & 0.0270 & -0.0154 & 0.0207 & 0.0412 & -0.0300 & -0.0071 & -0.0023 & -0.0008 \\
\hline “smp $(-1)$ " & -0.0021 & 0.0286 & -0.0120 & 0.0046 & 0.0030 & -0.0044 & 0.0244 & -0.0357 & -0.2271 & 0.0020 & 0.0429 \\
\hline "load(-1)" & 0.3564 & -0.4768 & -0.0046 & 0.0863 & 0.1917 & -0.0644 & 0.1848 & 0.1352 & -0.1476 & -0.3191 & 0.4495 \\
\hline "lignite(-1)" & -0.0492 & 0.0956 & 0.0600 & 0.0427 & -0.0283 & -0.0276 & -0.0196 & 0.0236 & -0.2920 & 0.0042 & -0.1234 \\
\hline
\end{tabular}

